\title{
Selection and Assessment of Passive Cooling Techniques for Residential Buildings in Oman Using a Bioclimatic Approach
}

\author{
N Al-Azri*a, YH Zurigatb and N Al-Rawahia \\ ${ }^{a}$ Mechanical and Industrial Engineering Department, College of Engineering, Sultan Qaboos University, PO Box 33, PC \\ 123, Al-Khoud, Muscat - Sultanate of Oman \\ ${ }^{b}$ Mechanical Engineering Department, American Universty of Sharjah, PO Box 26666, UAE
}

Received 9 July 2011; accepted 29 January 2013

\begin{abstract}
Passive cooling is an ancient technique used in air reconditioning and ventilation. Despite its historical use, its relevance in building design has never ceased. To be sure, with the increasing interest in saving energy and preserving the environment, passive cooling stands out as a sustainable possibility. However, this is not always a viable option, and its practicality is determined mainly by the system's functionality, the type of activities involved in the space to be cooled, and the surrounding area's bioclimatic variables (i.e. temperature, humidity, and diurnal temperature differences). In areas under consideration for passive cooling systems, bioclimatic charts are helpful. Comprehensive charts, in which yearlong hourly meteorological data are projected on a psychrometric chart, help to determine the fits required by a particular location. In this paper, psychrometric charts were developed for eight locations in Oman, and a systematic procedure on the selection and viability of using passive cooling techniques is provided through meteorological data. Givoni's passive cooling zones are used and the applicability of each technique is quantified. The eight study locations are widely scattered around and Oman, and possess great geographical diversity. The presented results can help delineate the applicability of each passive cooling technique for residential buildings at each of the study locations and their proximities.
\end{abstract}

Keywords: Thermal comfort zone, Bioclimatic chart, Evaporative cooling, Ventilation, High mass

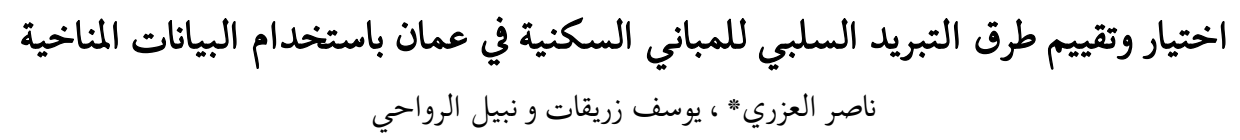

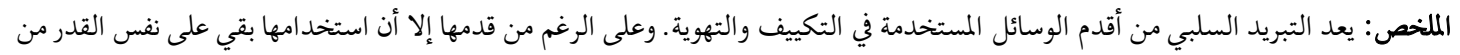

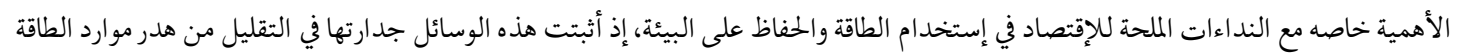

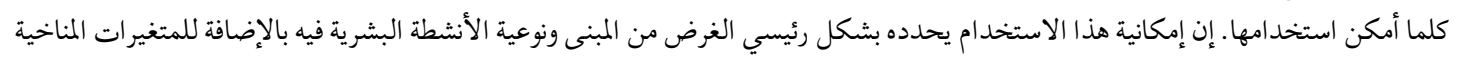

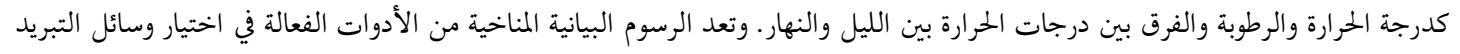

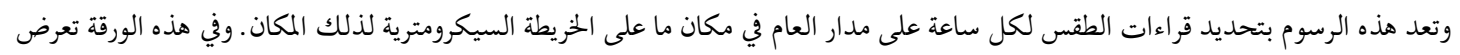

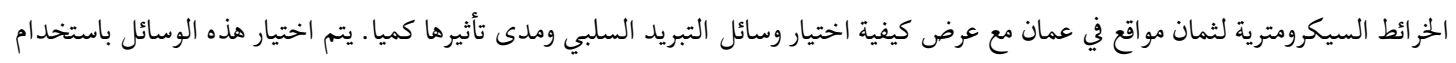

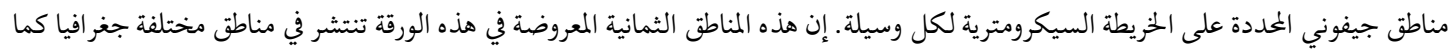
إن النتائج المعروضة تحدد وسائل التبريد السلبي الممكنة لهذه المناطق والأماكن القريبة منها. الكلمات المفتاحية: منطقة الإرتياح الحراري، الرسوم البيانية المناخية، التبريد بالتبخر، التهوية، الكتل الحرارية

$\overline{\text { *Corresponding author's e-mail: nalazri@squ.edu.om }}$ 


\section{Introduction}

According to the International Energy Agency (IEA), world electricity demand will double by 2030 as compared to the demand of 2006, with an average growing rate of $2.6 \%$. This increase will be accompanied by a $75 \%$ increase in $\mathrm{CO}_{2}$ emissions. The huge increase is mainly attributable to manufacturing development in the third world, in addition to the increase in population (IEA 2006). Climate change and soaring fossil fuel prices, in addition to the uncontrollable growth of energy demand, are putting renewable resources in more demand than ever. The world investment in renewable energy is increasing rapidly. It was US\$ 211 billion in 2010 compared to only US\$ 33 billion in 2006, with an average growth rate of $39 \%$. The renewable energies sectors with the highest growth rates are wind and solar (UNEP 2011).

In Oman, air conditioning consumes more energy than any other electrical appliance. In the hottest six months (April to September), energy consumption is double that of October to March. Unfortunately, drought and the dry nature of the country pose an intractable constraint towards using solar cooling. Passive cooling techniques can offer good energy-saving opportunities at low or no additional cost.

\section{Passive Cooling Strategies}

Passive cooling techniques have been used on the Arabian Peninsula since antiquity. Intuitively, the definition of a passive cooling process is simply any process in which cooling takes place without the interaction of any externally powered system. A more technical definition is the use of renewable sources of energy to increase heat loss (Givoni 2009). Passive techniques are based on three basic strategies: mass effect, air movement, and evaporative cooling (Szokolay 2004). These strategies include a wide spectrum of applications.

\subsection{High Mass with Night Ventilation}

In hot climates, heavy external walls can retard the flow of heat by as many as 12 hours, especially when there is a difference between night and daytime temperatures, or diurnal range, which exceeds $6^{\circ} \mathrm{C}$ (Reardon 2010). The day-to-night temperature difference requirement makes thermal mass more effective in hot dry climates. When this temperature difference is beyond $10^{\circ} \mathrm{C}$, thermal mass can be an indispensable strategy.

Thermal mass can have a positive effect on thermal comfort. High-mass structures can limit a high interior temperature and sustain a steadier thermal environment. A material with a high mass increases comfort, especially during considerable air temperature changes where there is a significant difference between day and nighttime temperatures. The performance of the high mass materials is also influenced by the thermophysiccal properties of the construction material (Santamouris and Asimakopoulos 1996). For an effective storage of heat, density $(\rho)$, thermal heat capacity $\left(C_{p}\right)$, and thermal conductivity $(\lambda)$ should be selected properly. The increase in the value of the three parameters promotes a higher heat storage capacity. Porous materials with low specific heat exhibit a low thermal mass. Good thermal conductivity and low reflectivity are also required for effective passive cooling when thermal mass is used (Reardon 2010). Thus, with this in mind, reinforced concrete has a high thermal mass $\left(2060 \mathrm{~kJ} / \mathrm{m}^{3} \mathrm{~K}\right)$ while earth adobe has a low thermal mass $\left(1300 \mathrm{~kJ} / \mathrm{m}^{3} \mathrm{~K}\right)$.

Thermal diffusivity $\left(\lambda / \rho C_{\mathrm{P}}\right)$ decides the depth diurnal heat waves reach within the storage material, where $C_{\mathrm{p}}$ is the specific heat capacity of the material (Santamouris and Asimakopoulos 1996). For cooling, a proper tradeoff should be decided between thermal diffusivity and wall thickness. If the wall is too thick, this will delay the penetration of heat to the interior until the next day.

The thermal mass effectiveness depends on the construction material as well as the thickness of its construction. Thermal mass is basically the density times the specific heat $\left(C_{\mathrm{p}} . \rho\right)$ measured in units of kilojoules $\left(\mathrm{kJ} / \mathrm{m}^{3} \mathrm{~K}\right)$ or British thermal units $\left(\mathrm{Btu} / \mathrm{ft}^{3} \mathrm{R}\right)$. Hence, the construction thickness $(\mathrm{L})$ is the second factor that comes in to play. When high thermal mass is desirable, the thickness has to be economically justified; hence, one should consider calculating $\left(L . C_{\mathrm{p}} . \rho\right)$ and selecting the optimal tradeoff when capitalizing on thick construction while saving energy.

In regions where there is a significant difference between day and nighttime temperatures, night ventilation is used to cool the building so that it can tolerate the daytime heat gain. The ventilation process can be carried out naturally or forced using fans. Night cooling allows the thermal mass to absorb the heat gain of the next day. During the daytime, when the exterior is hotter than the interior, the thermal mass decelerates the penetration of the heat to the interior. The nighttime ventilation gets rid of that daytime heat gain (Shaviv et al. 2001).

The use of air movement as a cooling means is an intuitive and essential passive cooling strategy. Wind provides cooling through air circulation and evaporative cooling. It is applicable in all types of climates but is less effective in tropical climates at high humidity. At moderate temperature values, a wind blowing at a 
fraction of a meter per second can have a cooling effect equivalent to a few degrees centigrade at $50 \%$ humidity (Reardon 2010). At higher humilities, the speed has to be more in order to have the same cooling effect.

Ventilation is basically the process in which indoor air is refined by circulation or replacement with outdoor air. The ventilation process can be either mechanically operated or natural. In natural ventilation, air is allowed to circulate through open windows or by trickle vents. The American Society of Heating, Refrigerating and Air Conditioning Engineers (ASHRAE 2009) define ventilation air as the air used for providing quality indoor air. In night ventilation, the accumulated heat during the day is decreased, allowing cold air to enter the building. The cold air replaces the hot air naturally with the help of wind and the stack effect (thermal buoyancy). This cooling process is based on convective heat transfer from the exposed building surfaces (Breesch and Janssens 2007; 2010). Night ventilation is most effective in moderate to hot climates with a significant diurnal temperature difference and low humidity (Kolokotroni 1995).

\subsection{Evaporative Cooling}

As its name suggests, evaporative cooing is based on eliminating heat through the evaporation of water. Evaporative cooling can either be direct or indirect. In the direct method, the hot air stream passes through a wet structure where it loses some of its heat through the evaporation of moisture and also increases its moisture content. The discharged cold stream will have a lower dry bulb temperature than the hot stream, but the same wet bulb temperature.

In the indirect method, the purpose is only to decrease the air dry bulb temperature without increasing the moisture content. In this method, the hot stream will first be cooled using the direct evaporative method and then it will be used to cool the room air in a heat exchanger. Because evaporative cooling is based on saturating air with moisture, it is mostly effective in dry climates where there is enough room moisture to be absorbed by air. In this way, evaporation takes place.

\section{Thermal Comfort}

Human thermal comfort is relative and is almost impossible to define with high accuracy due to individual, climatic, and cultural differences. For instance, people living in naturally ventilated, unconditioned buildings usually have more tolerance to wide changes in the temperature of a summer day (Givoni 1992).

Macpherson (1973) specified six factors that can impact the sensation of comfort: air speed, mean radi- ant temperature (MRT), metabolic rate, temperature, and humidity, in addition to the individual's clothing level. Fanger (1972), however, suggested a model that takes into consideration of human factors. In addition to the environmental variables, he considered people's activity and clothing levels. His predicted mean vote (PMV) model was experimentally derived from the responses of college-age subjects set in a uniform environment with conditions held steady. The group's PMV was defined as the predicted mean of votes raised by any large population expressing their thermal sensation in any given environment.

Because of the diversity in the governing variables that affect comfort, there has not been an exact definition of a comfort zone (CZ). In the PMV model, comfort was graded qualitatively using a seven-point scale ranked the same as the (ASHRAE 2009) scale: cold, cool, slightly cool, neutral, slightly warm, warm, and hot. However, the quantitative scaling of this method ascends from -3 to 3 instead of going from 1 to 7 as in the case of ASHRAE's scale. Macpherson (1973) suggested a 19-grade index that is a function of one or more of the six factors impacting the level of comfort.

In spite of these differences, there is a range of humidity and temperature values within which the vast majority of people will feel thermally comfortable. Different authors might vary slightly their delineation of the boundaries of a thermal zone, but they all agree on a vast common portion. The CZ set by (ASHRAE 2009) assumes no consideration to people's acclimatization to different climates.

According to ASHRAE Standard 55, thermal neutrality is defined as the indoor thermal index value corresponding with a mean vote of neutral on the thermal sensation scale. Earlier works defined temperatures at which thermal neutrality is achieved and is correlated to the external air temperature. Comfort is achieved at these temperature values provided that other factors such as humidity and clothing are satisfied. Humphreys (1978) carried out lab and field experiments in order to estimate thermal neutrality. He defined neutral temperature as a function of outdoor temperature using the correlation

$$
T_{\text {neutrality }}=11.9+0.534 T_{\text {outdoor }}
$$

Similar to that of Humphreys, Auliciems (1981) approach considers thermal neutrality as a function of the mean outdoor temperature using the correlation

$$
T_{\text {neutrality }}=17.6+0.31 T_{\text {outdoor }}
$$

The operative temperature ranges between 17.8 and $29.5^{\circ} \mathrm{C}$. The validity of the neutrality is also dictated by ASHRAE standard 55-81, which bounds the moisture content within $4-125 / \mathrm{kg}$ DA, and also relative 


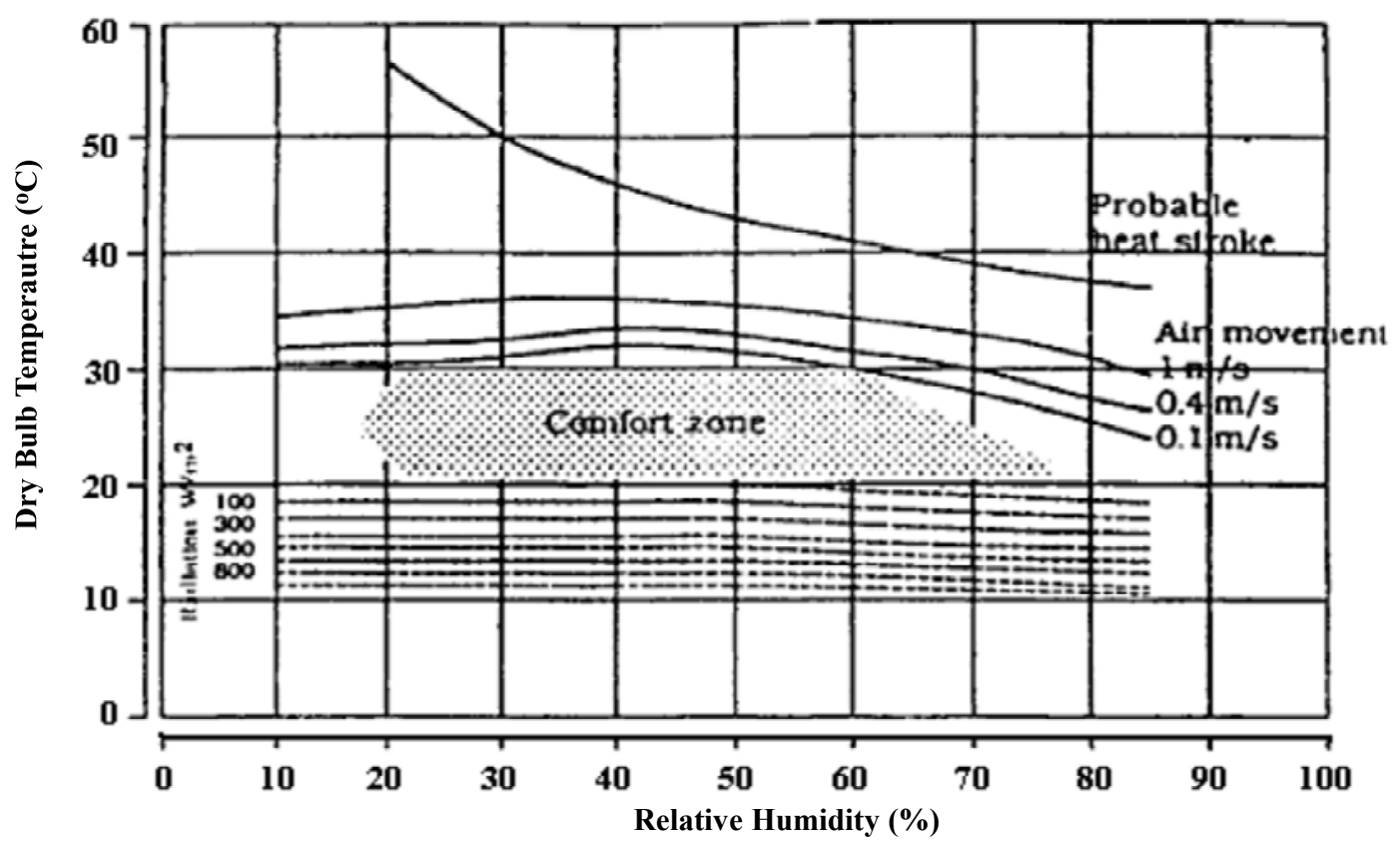

Figure 1. Olgyay's bioclimatic chart (Olgyay, 1963)

humidity not exceeding 90\%. Another method that deals with heating and cooling loads in relation to the outdoor conditions is the degree day method. This method can be defined as the annual cumulative timeweighted temperature (Sayigh et al. 1998).

In this method, a reference indoor temperature is set and the difference between the reference temperature and the mean daily outdoor temperature is calculated for the whole year to obtain heating degree-days and cooling-degree days. This method is very useful when the order of the yearly cooling load is to be compared from one year to another for the same location (Sayigh et al. 1998).

\section{Building Bioclimatic Charts}

Building bioclimatic charts offers a convenient way to predict whether or not a passive cooling technique is likely to improve the level of comfort in a building. The selection of a building's possible passive thermal design strategies is based heavily on the local climatic conditions. Identifying a suitable strategy for any given location can be done using bioclimatic charts. Building bioclimatic charts offers a convenient way to predict whether or not a passive cooling technique is likely to improve the level of comfort in a building.

Olgyay's bioclimatic chart (Fig. 1), developed in the 1950 's, was one of the earliest attempts to specify different strategies at different combinations of relative humidity (as abscissa) and dry bulb temperatures (as ordinate). Oglyay's chart sets the CZ between 20 and $30^{\circ} \mathrm{C}$. The level of comfort is applicable to indoor spaces where occupants are wearing indoor clothing. The $\mathrm{CZ}$ is shown at the center of Olgyay's chart. The chart shows the effect of climatic factors such as the mean radiant temperature, wind speed, and solar radiation on thermal comfort. Above the lower boundary of the zone, shading is necessary to maintain a reasonable level of comfort. Up to $10^{\circ} \mathrm{C}$ below the $\mathrm{CZ}$, comfort can be retained provided that there is enough solar radiation to offset the decrease in temperature. Likewise, to retain comfort up to around $10^{\circ} \mathrm{C}$ above the zone, wind speed can offset the increase in temperature. Evaporative cooling according to this chart is another means to retain comfort at high temperature values but at low humidity.

Since Olgyay's chart only considers the outdoor conditions and disregards the indoor physiological considerations, it is only applicable for hot humid climates where there is minimal fluctuation between the indoor and outdoor temperatures. This limits its application to low-mass ventilated buildings (Sayigh et al. 1998).

Another approach that disregards building parameters and is based on calculating degree-hours with variable building temperature is the climatic cooling potential (CCP) (Artmann et al. 2007). The buildingspecific parameters are disregarded so as to enhance the generality of the method. CCP is defined as the mean of the products of the temperature difference between building and external air by the time interval for $\mathrm{N}$ nights. To be considered in the mean calculation, the temperature difference has to achieve a threshold value when night ventilation is applied. This value was set at $3 \mathrm{~K}$ in Artmann's study. The building temperature is assumed to oscillate harmonically within the range of $24.5 \pm 2.5^{\circ} \mathrm{C}$. This range reflects the recommendation for thermal comfort in offices. The variation in the 


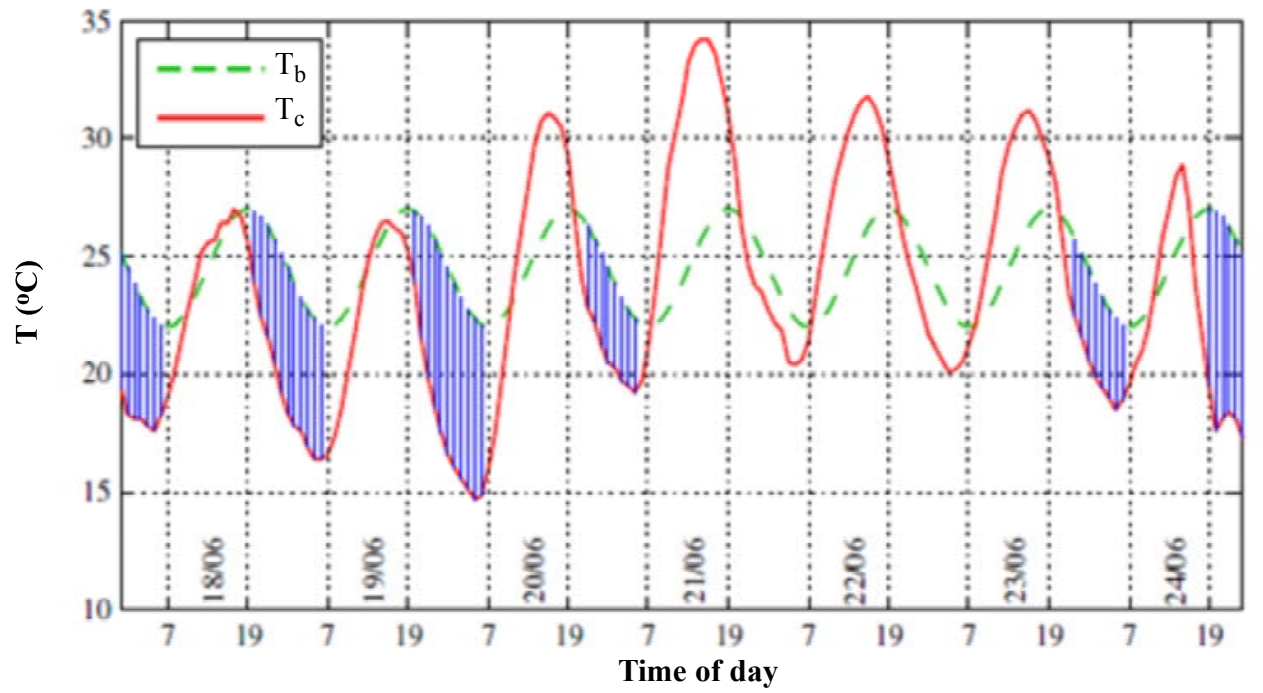

Figure 2. Climate cooling potential (CCP) for Zurich, Switzerland during one week in summer 2003 (Artmann et al. 2007)

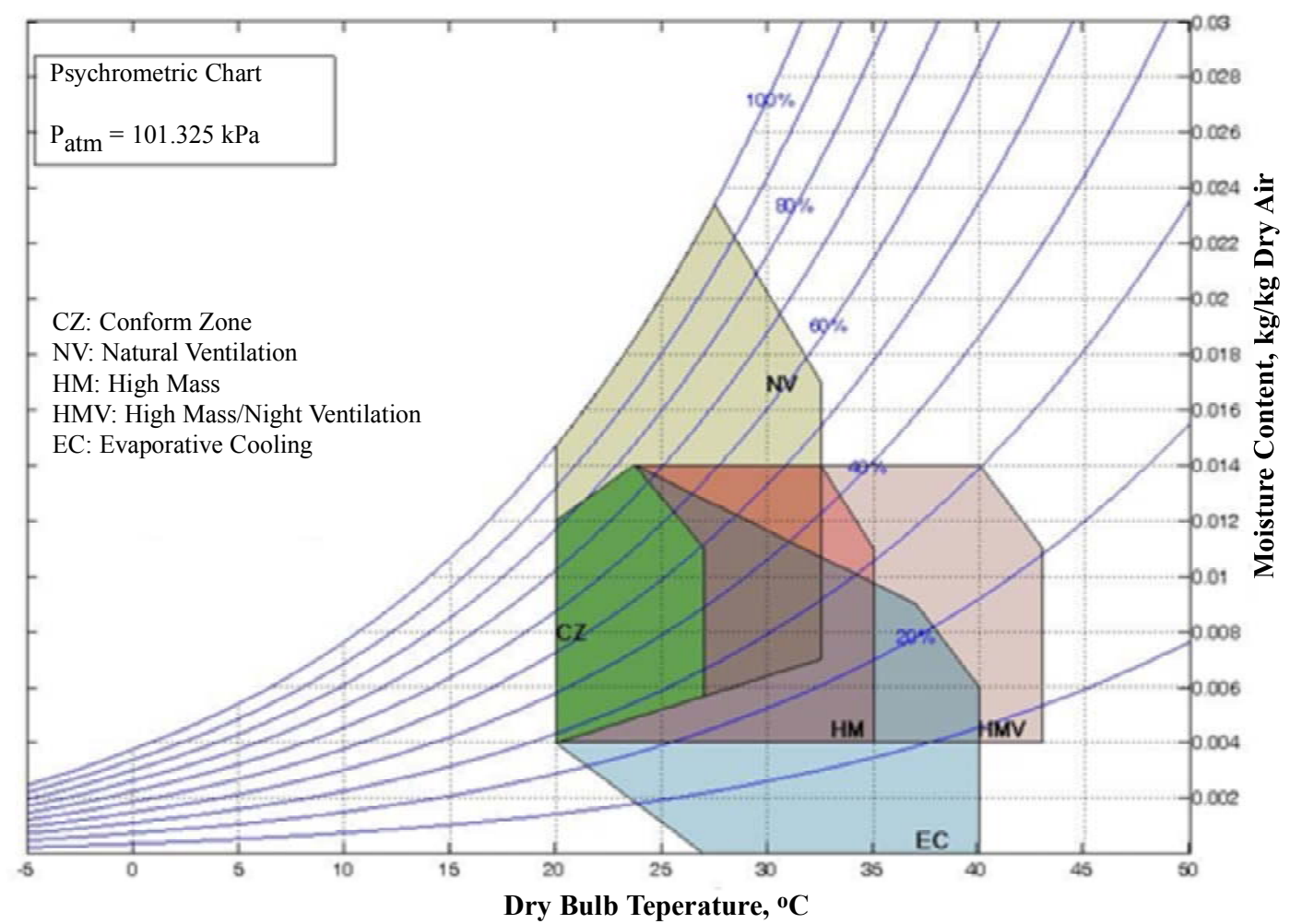

Figure 3. Typical building bioclimatic charge (Givoni 1992)

CCP model is represented by a cosine-function of the difference in hours between a given hour and the initial hour for time ventilation.

Figure 2 shows the application of the method to Zurich, Switzerland. The shaded areas represent passive cooling opportunities which happened to occur at times when the difference between the building temperature $\left(T_{b}\right)$ and external air temperature $\left(T_{e}\right)$ exceeded the threshold.
Another graphical method based on the psychrometric chart is the control potential zone (CPZ) by (Szokolay 1986). This method applied Auliciems' (1981) approach of the adaptive thermal comfort discussed above. The CPZ approach depends on the location and people's thermal sensation at that particular location.

A simplified method for anticipating cooling load is based on the hourly difference between the air temper- 


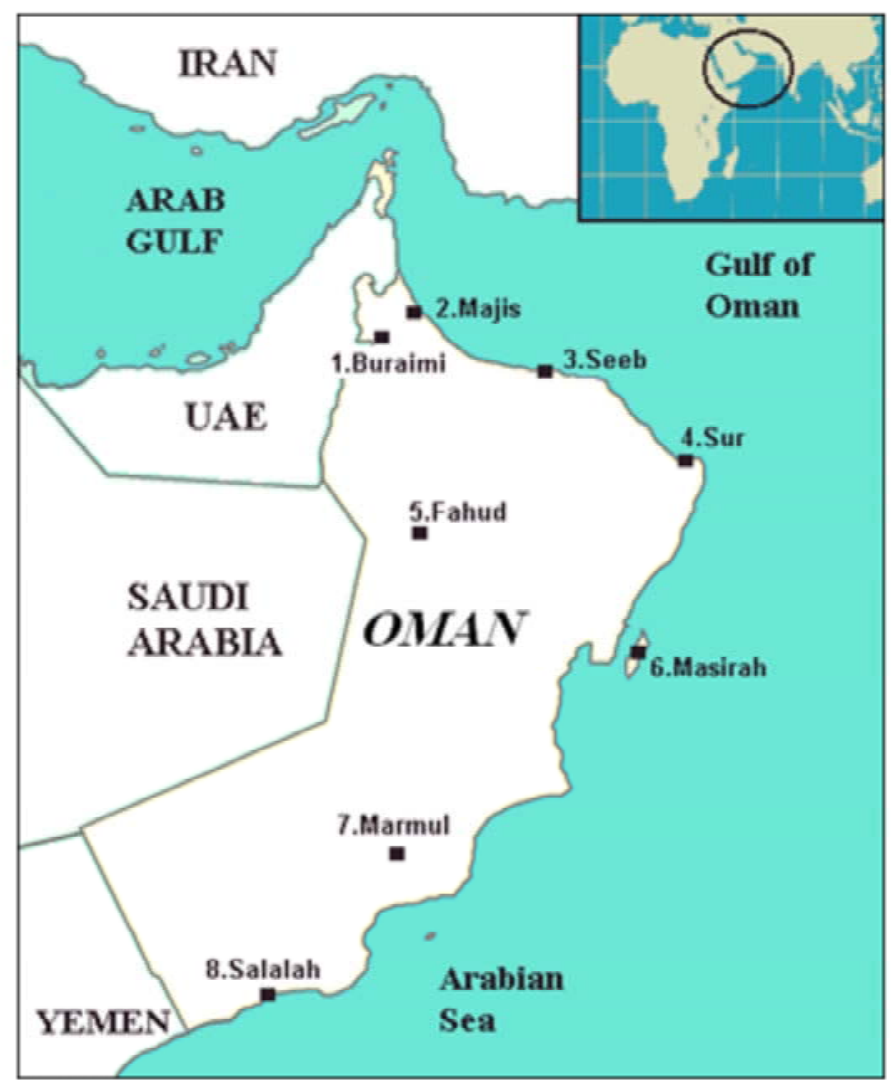

Figure 4. The map of Oman and the studied locations on the map

Table 1. The geographic location of the studied locations

\begin{tabular}{lcccccccc}
\hline Location & \multicolumn{3}{c}{ Latitude 'N' } & \multicolumn{3}{c}{ Longitude 'E' } & $\begin{array}{c}\text { Elevation } \\
\text { (m) }\end{array}$ & $\begin{array}{c}\text { Pressure } \\
\mathbf{N} / \mathbf{m}^{2}\end{array}$ \\
& Deg. & Min. & Sec. & Deg. & Min. & Sec. & $(\mathbf{m})$ & 97,786 \\
1. Buraimi & 24 & 14 & 29.1 & 55 & 47 & 13.8 & 299 & 101,281 \\
2. Majis & 24 & 28 & 1.0 & 56 & 38 & 27.1 & 4 & 101,224 \\
3. Seeb & 23 & 35 & 0.0 & 58 & 17 & 0.0 & 8 & 101,160 \\
4. Sur & 22 & 32 & 15.6 & 59 & 28 & 31.0 & 14 & 99,299 \\
5. Fahud & 22 & 20 & 53.0 & 56 & 29 & 14.0 & 170 & 101,099 \\
6. Masirah & 20 & 40 & 0.0 & 58 & 54 & 0.0 & 19 & 98,135 \\
7. Marmul & 18 & 08 & 23.0 & 55 & 10 & 39.0 & 269 & 101,085 \\
8. Salalah & 17 & 02 & 0.0 & 54 & 05 & 0.0 & 20 & \\
\hline
\end{tabular}

ature and a base temperature-the cooling degree hours and days (Hasse and Amato 2009). The degree days are obtained by summing up the degree hours from one day. The number of cooling degree days in a given period represent the cooling load required.

Other popular bioclimatic approaches are those of (Givoni 1992, 1994 and Lomas et al. 2004). The chart was based on the linear relationship between the temperature amplitude and vapor pressure of the outdoor air (Sayigh et al. 1998). Unlike other bioclimatic charts, this chart is laid on the familiar psychrometric chart and preserves the relevant psycrometric parameters which are essential to the selection of passive cooling strategies. The development of the Givoni chart was based on experimental research on buildings in Europe and the USA. These buildings were characterized by their low heat gain; therefore, the reliability of the charts for thermally heavyweight buildings is questionable (Givoni 1994; Lomat et al. 2004).

Givoni's chart (Fig. 3) is mainly applicable to residential and office buildings where heat gain is minimal (Watson 1981). Modifications to Givoni's chart that suit nondomestic buildings can also be found in the literature (Lomas et al. 2004). The natural ventilation zone on Givoni's chart assumes that the indoor mean radiant temperature and the vapor pressure are the 


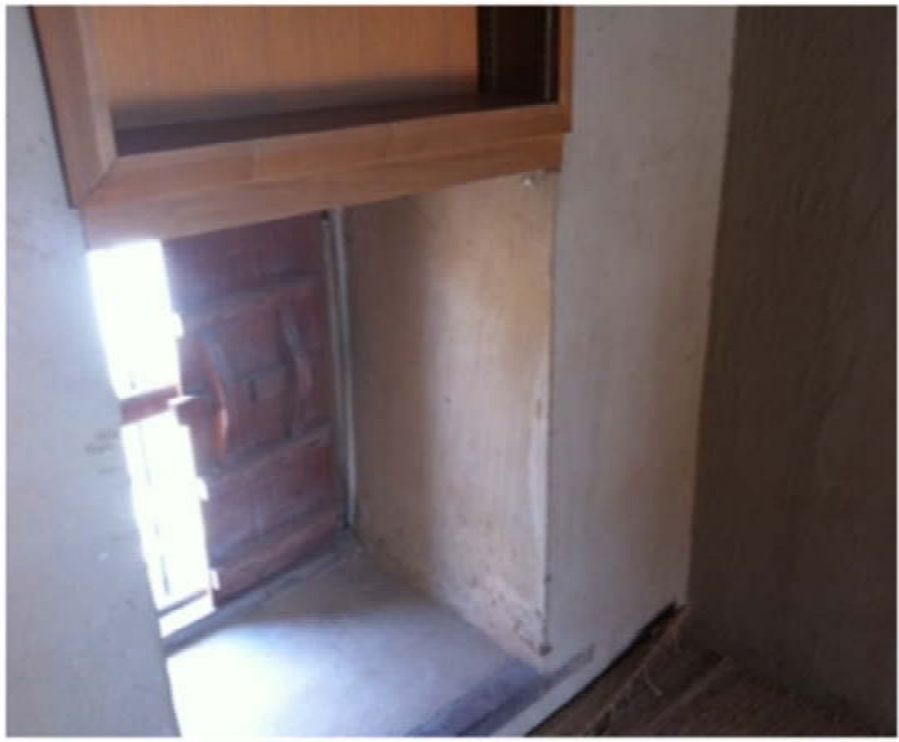

Figure 5. Thermal mass in the old building structures in Oman

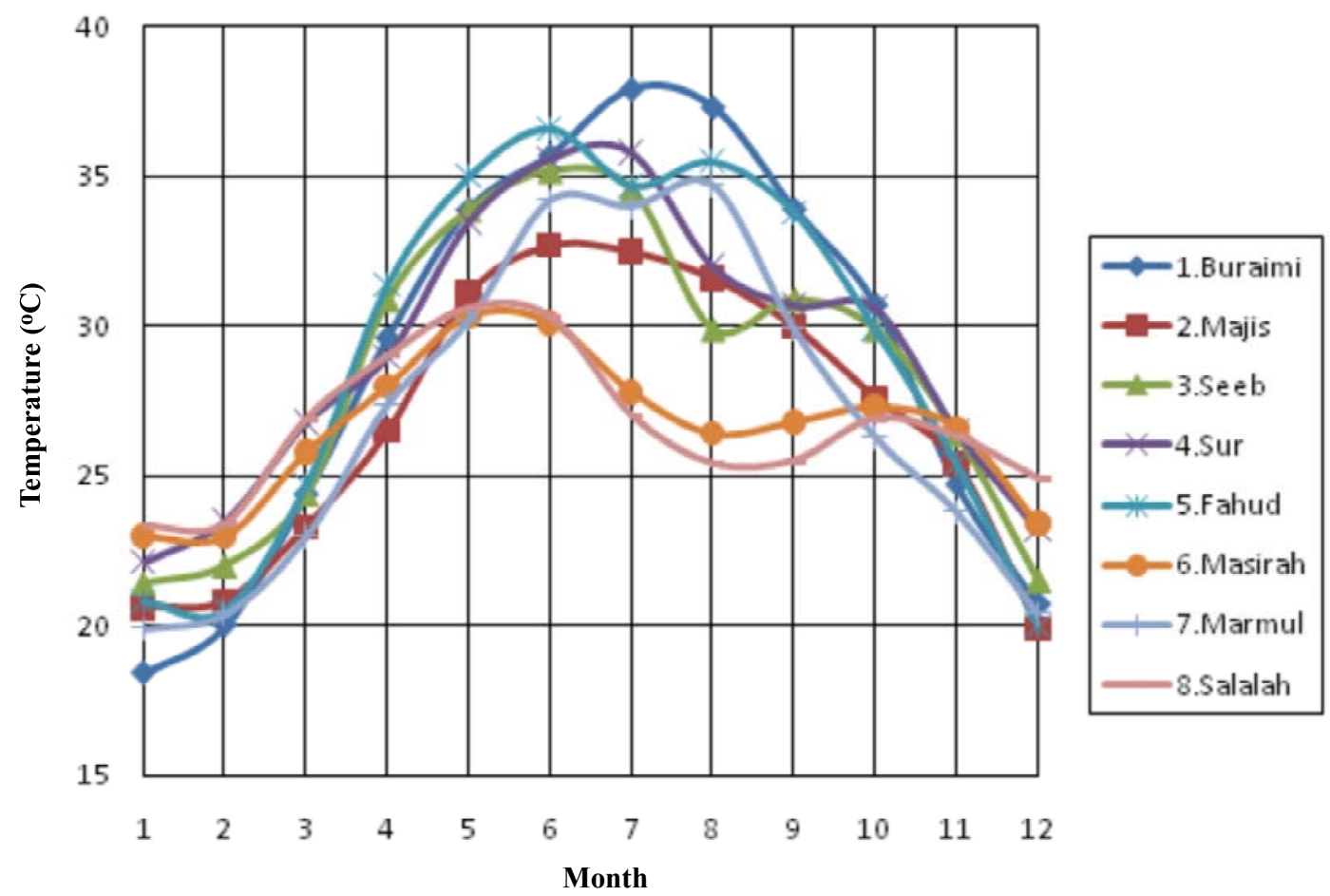

Figure 6. The average monthly dry-bulb temperature of the eight locations

same of those at outdoor conditions. This assumption limits the application to buildings with medium to high thermal mass (Watson 1981).

At high temperatures, mechanical air conditioning is necessary to maintain a habitable environment within buildings. On the left of the $\mathrm{CZ}$, heating is needed to restore comfort using either solar or mechanical heating. The high thermal mass effect is provided by heavy construction material that helps absorb heat and can be reversed in direction overnight (Szokolay 2004). If the climate is hot and dry, night ventilation will help by releasing heat through windows, assisted by fans if necessary.

Due to their simplicity and preservation of all psychrometric parameters, Givoni's charts can be used in studying the application of passive cooling techniques in Oman.

\section{Application of Passive Cooling in Oman}

Oman is located in the tropical zone, in the northeastern Arabian Peninsula. Its mainland is bounded 


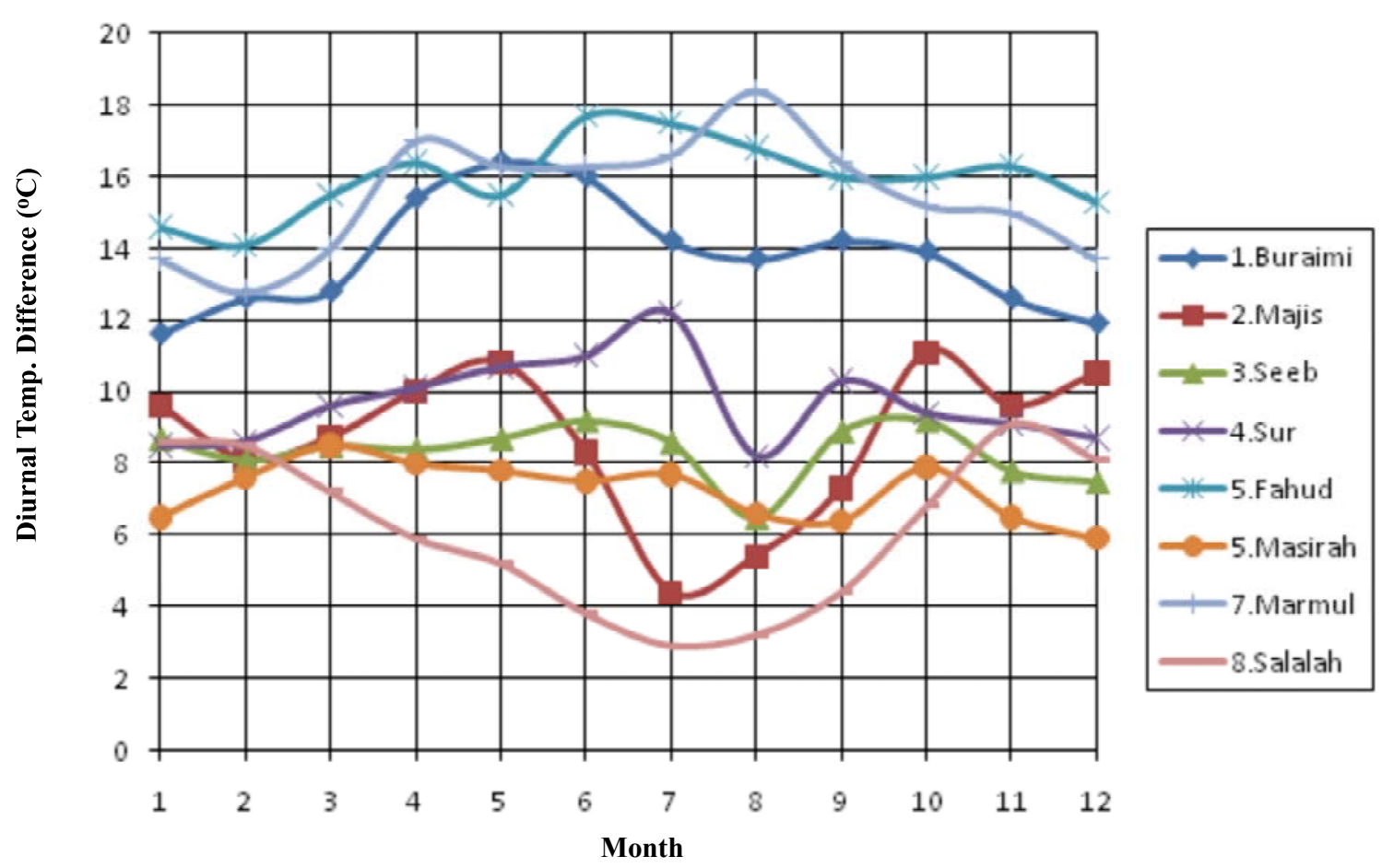

Figure 7. The average monthly day to night temperature difference

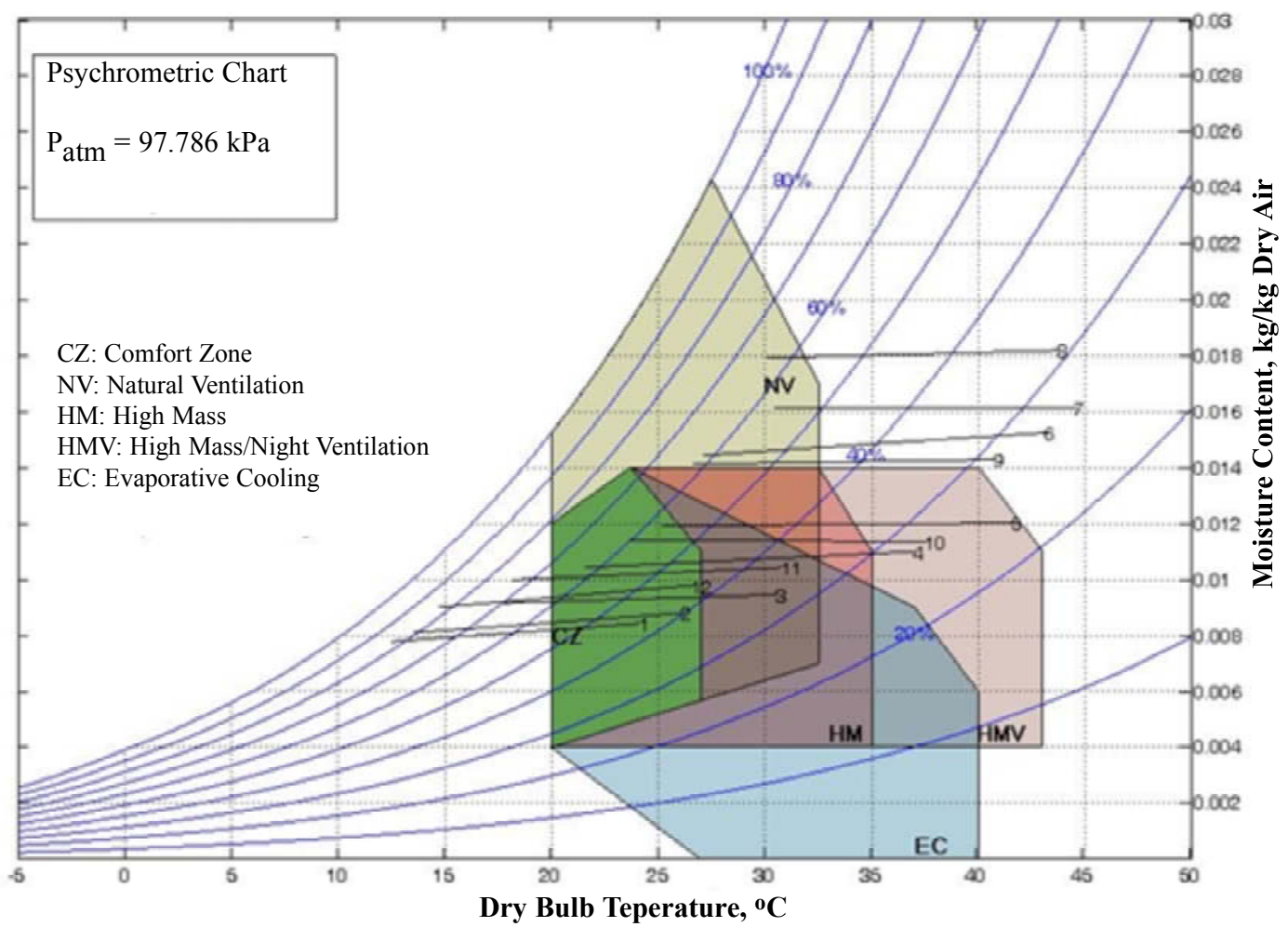

Figure 8. Givoni's bioclimatic chart for location (1), Buraimi

between $63^{\circ} 40^{\prime}$ and $57^{\circ} 0^{\prime}$ to the north and lies between $19^{\circ} 0^{\prime}$ and $22^{\circ} 30^{\prime}$ to the east (Fig. 4). The mainland has a coastline exceeding 1,700 kilometers and a diverse interior topography of arid desert, mountainous regions, and cultivable plains. In this study, the hourly climatic data of eight locations were analyzed in order to evaluate prospective passive cooling opportunities in these locations. The eight locations are scattered throughout the country, and this variability of location is one of the reasons that they were chosen. 
Table 2. Average monthly temperatures and humidity

\begin{tabular}{|c|c|c|c|c|c|c|}
\hline & $\begin{array}{c}\boldsymbol{T}_{d b, \text { mean }} \\
(\boldsymbol{C})\end{array}$ & $\begin{array}{l}W_{\text {mean }} \\
(\%)\end{array}$ & $\boldsymbol{T}_{d b, \text { day diff }}(\boldsymbol{C})$ & $\begin{array}{c}T_{d b, \text { mean }} \\
(C)\end{array}$ & $\begin{array}{c}W_{\text {mean }} \\
(\%)\end{array}$ & $\begin{array}{c}\boldsymbol{T}_{d b, d \text { iff } f} \\
(\boldsymbol{C})\end{array}$ \\
\hline & \multicolumn{3}{|c|}{ Buraimi (1) } & \multicolumn{3}{|c|}{ Majis (2) } \\
\hline Jan & 18.4 & 62 & 11.6 & 20.6 & 73 & 9.6 \\
\hline $\mathrm{Feb}$ & 20.0 & 58 & 12.6 & 20.8 & 80 & 8.1 \\
\hline Mar & 24.4 & 49 & 12.8 & 23.3 & 75 & 8.7 \\
\hline Apr & 29.6 & 42 & 15.4 & 26.5 & 62 & 10.0 \\
\hline May & 33.9 & 37 & 16.4 & 31.1 & 60 & 10.8 \\
\hline Jun & 35.7 & 41 & 16.0 & 32.7 & 69 & 8.3 \\
\hline Jul & 37.9 & 39 & 14.2 & 32.5 & 81 & 4.4 \\
\hline Aug & 37.3 & 45 & 13.7 & 31.6 & 81 & 5.4 \\
\hline Sep & 33.9 & 43 & 14.2 & 30.0 & 81 & 7.3 \\
\hline Oct & 30.7 & 42 & 13.9 & 27.6 & 68 & 11.1 \\
\hline Nov & 24.7 & 53 & 12.6 & 25.4 & 72 & 9.6 \\
\hline \multirow[t]{2}{*}{ Dec } & 20.7 & 61 & 11.9 & 19.9 & 75 & 10.5 \\
\hline & \multicolumn{3}{|c|}{ Seeb (3) } & \multicolumn{3}{|c|}{ Sur (4) } \\
\hline Jan & 21.4 & 57 & 8.7 & 22.1 & 74 & 8.5 \\
\hline $\mathrm{Feb}$ & 22.0 & 61 & 8.1 & 23.5 & 72 & 8.6 \\
\hline Mar & 24.4 & 61 & 8.5 & 26.8 & 62 & 9.6 \\
\hline Apr & 30.9 & 42 & 8.4 & 29.0 & 55 & 10.1 \\
\hline May & 33.9 & 45 & 8.7 & 33.5 & 53 & 10.7 \\
\hline Jun & 35.2 & 48 & 9.2 & 35.6 & 47 & 11.0 \\
\hline Jul & 34.6 & 54 & 8.6 & 35.8 & 49 & 12.2 \\
\hline Aug & 29.9 & 74 & 6.5 & 32.0 & 67 & 8.2 \\
\hline Sep & 30.9 & 63 & 8.9 & 30.7 & 66 & 10.3 \\
\hline Oct & 29.9 & 55 & 9.2 & 30.6 & 59 & 9.4 \\
\hline Nov & 26.4 & 58 & 7.8 & 26.5 & 63 & 9.1 \\
\hline \multirow[t]{2}{*}{ Dec } & 21.5 & 61 & 7.5 & 23.2 & 66 & 8.7 \\
\hline & \multicolumn{3}{|c|}{ Fahud (5) } & \multicolumn{3}{|c|}{ Masira (6) } \\
\hline Jan & 20.8 & 50 & 14.6 & 23.0 & 71 & 6.5 \\
\hline $\mathrm{Feb}$ & 20.5 & 52 & 14.1 & 23.0 & 69 & 7.6 \\
\hline Mar & 24.7 & 42 & 15.5 & 25.8 & 80 & 8.5 \\
\hline Apr & 31.4 & 29 & 16.4 & 28.0 & 77 & 8.0 \\
\hline May & 35.0 & 26 & 15.5 & 30.3 & 76 & 7.8 \\
\hline Jun & 36.6 & 27 & 17.7 & 30.1 & 81 & 7.5 \\
\hline Jul & 34.7 & 34 & 17.5 & 27.8 & 76 & 7.7 \\
\hline Aug & 35.5 & 40 & 16.8 & 26.4 & 81 & 6.6 \\
\hline Sep & 33.8 & 39 & 16.0 & 26.8 & 81 & 6.4 \\
\hline Oct & 29.9 & 36 & 16.0 & 27.3 & 72 & 7.9 \\
\hline Nov & 25.4 & 41 & 16.3 & 26.6 & 79 & 6.5 \\
\hline \multirow[t]{2}{*}{ Dec } & 20.0 & 57 & 15.3 & 23.4 & 62 & 5.9 \\
\hline & \multicolumn{3}{|c|}{ Marmul (7) } & \multicolumn{3}{|c|}{ Salalah (8) } \\
\hline Jan & 19.9 & 66 & 13.7 & 23.3 & 54 & 8.6 \\
\hline $\mathrm{Feb}$ & 20.4 & 54 & 12.8 & 23.4 & 52 & 8.5 \\
\hline Mar & 23.0 & 57 & 14.0 & 26.9 & 60 & 7.2 \\
\hline Apr & 27.4 & 48 & 17.0 & 29.0 & 70 & 5.9 \\
\hline May & 30.2 & 55 & 16.3 & 30.6 & 72 & 5.2 \\
\hline Jun & 34.2 & 36 & 16.3 & 30.3 & 81 & 3.8 \\
\hline Jul & 34.0 & 38 & 16.6 & 27.0 & 87 & 2.9 \\
\hline Aug & 34.7 & 26 & 18.4 & 25.4 & 91 & 3.2 \\
\hline Sep & 29.9 & 52 & 16.4 & 25.5 & 80 & 4.4 \\
\hline Oct & 26.3 & 51 & 15.2 & 26.9 & 67 & 6.8 \\
\hline Nov & 23.8 & 60 & 15.0 & 26.3 & 60 & 9.1 \\
\hline Dec & 20.4 & 65 & 13.7 & 24.9 & 55 & 8.1 \\
\hline
\end{tabular}


N Al-Azri, YH Zurigat and N Al-Rawahi

Table 3. Average maximum and minimum temperatures and relative humidity

\begin{tabular}{|c|c|c|c|c|c|c|c|c|}
\hline & $\begin{array}{c}\overline{\mathrm{T}}_{\mathrm{db}, \max } \\
\left({ }^{\circ} \mathrm{C}\right)\end{array}$ & $\begin{array}{c}\overline{\mathrm{T}}_{\mathrm{db}, \text { min }} \\
\left({ }^{\circ} \mathrm{C}\right)\end{array}$ & $\begin{array}{c}\bar{\phi}_{\max } \\
(\%)\end{array}$ & $\begin{array}{c}\bar{\phi}_{\min } \\
(\%)\end{array}$ & $\begin{array}{c}\overline{\mathrm{T}}_{\mathrm{db}, \max } \\
\left({ }^{\circ} \mathrm{C}\right)\end{array}$ & $\begin{array}{c}\overline{\mathrm{T}}_{\mathrm{db}, \text { min }} \\
\left({ }^{\circ} \mathrm{C}\right)\end{array}$ & $\begin{array}{l}\bar{\phi}_{\max } \\
(\%)\end{array}$ & $\begin{array}{c}\bar{\phi}_{\text {min }} \\
(\%)\end{array}$ \\
\hline & \multicolumn{4}{|c|}{ Buraimi (1) } & \multicolumn{4}{|c|}{ Majis (2) } \\
\hline Jan & 24.1 & 12.5 & 83 & 43 & 25.3 & 15.7 & 89 & 56 \\
\hline Feb & 26.1 & 13.5 & 81 & 40 & 24.7 & 16.5 & 94 & 64 \\
\hline Mar & 30.5 & 17.7 & 70 & 34 & 27.3 & 18.7 & 91 & 56 \\
\hline Apr & 37.0 & 21.6 & 63 & 27 & 31.0 & 21.0 & 80 & 42 \\
\hline May & 41.6 & 25.2 & 57 & 23 & 36.3 & 25.5 & 80 & 33 \\
\hline Jun & 43.1 & 27.1 & 62 & 27 & 36.4 & 28.1 & 87 & 48 \\
\hline Jul & 44.6 & 30.4 & 57 & 26 & 34.8 & 30.4 & 90 & 69 \\
\hline Aug & 43.8 & 30.1 & 64 & 31 & 34.4 & 29.0 & 91 & 69 \\
\hline Sep & 40.8 & 26.6 & 62 & 29 & 33.4 & 26.2 & 93 & 67 \\
\hline Oct & 37.5 & 23.6 & 60 & 27 & 32.9 & 21.8 & 86 & 47 \\
\hline Nov & 30.8 & 18.2 & 74 & 36 & 30.0 & 20.4 & 86 & 55 \\
\hline \multirow[t]{2}{*}{ Dec } & 26.6 & 14.7 & 83 & 43 & 25.1 & 14.6 & 89 & 58 \\
\hline & \multicolumn{4}{|c|}{ Seeb (3) } & \multicolumn{4}{|c|}{ Sur (4) } \\
\hline Jan & 25.4 & 16.7 & 74 & 40 & 26.3 & 17.9 & 92 & 52 \\
\hline Feb & 25.9 & 17.8 & 78 & 42 & 28.3 & 19.7 & 88 & 50 \\
\hline Mar & 28.7 & 20.2 & 83 & 40 & 32.3 & 22.7 & 86 & 34 \\
\hline Apr & 35.3 & 26.9 & 62 & 27 & 34.6 & 24.5 & 83 & 31 \\
\hline May & 38.4 & 29.7 & 67 & 26 & 39.9 & 29.2 & 74 & 29 \\
\hline Jun & 40.0 & 30.9 & 74 & 26 & 42.1 & 31.1 & 66 & 25 \\
\hline Jul & 39.0 & 30.5 & 80 & 32 & 42.8 & 30.6 & 68 & 29 \\
\hline Aug & 33.5 & 27.1 & 91 & 52 & 36.8 & 28.6 & 83 & 49 \\
\hline Sep & 35.6 & 26.7 & 82 & 38 & 36.9 & 26.6 & 84 & 42 \\
\hline Oct & 35.0 & 25.8 & 77 & 32 & 36.0 & 26.6 & 80 & 37 \\
\hline Nov & 30.4 & 22.6 & 74 & 41 & 31.5 & 22.4 & 81 & 39 \\
\hline \multirow[t]{2}{*}{ Dec } & 25.2 & 17.7 & 76 & 45 & 27.7 & 19.0 & 81 & 46 \\
\hline & \multicolumn{4}{|c|}{ Fahud (5) } & \multicolumn{4}{|c|}{ Masira (6) } \\
\hline Jan & 28.2 & 13.6 & 82 & 24 & 26.5 & 19.9 & 85 & 54 \\
\hline Feb & 27.6 & 13.5 & 87 & 23 & 27.0 & 19.4 & 86 & 49 \\
\hline Mar & 32.6 & 17.1 & 84 & 12 & 30.3 & 21.8 & 95 & 56 \\
\hline Apr & 39.4 & 22.9 & 54 & 13 & 32.5 & 24.6 & 94 & 53 \\
\hline May & 42.0 & 26.6 & 54 & 11 & 35.0 & 27.2 & 92 & 53 \\
\hline Jun & 45.1 & 27.5 & 58 & 10 & 34.6 & 27.1 & 94 & 61 \\
\hline Jul & 44.3 & 26.8 & 62 & 9 & 32.5 & 24.9 & 90 & 57 \\
\hline Aug & 44.0 & 27.2 & 75 & 15 & 30.3 & 23.7 & 93 & 65 \\
\hline Sep & 41.8 & 25.8 & 69 & 18 & 30.6 & 24.2 & 93 & 64 \\
\hline Oct & 37.6 & 21.6 & 63 & 19 & 31.8 & 23.9 & 90 & 48 \\
\hline Nov & 33.7 & 17.5 & 72 & 19 & 30.3 & 23.7 & 92 & 60 \\
\hline \multirow[t]{2}{*}{ Dec } & 27.7 & 12.3 & 89 & 32 & 26.7 & 20.7 & 75 & 48 \\
\hline & \multicolumn{4}{|c|}{ Marmul (7) } & \multicolumn{4}{|c|}{ Salalah (8) } \\
\hline Jan & 26.9 & 13.2 & 90 & 39 & 27.6 & 19.0 & 74 & 35 \\
\hline Feb & 27.3 & 14.4 & 79 & 25 & 27.5 & 19.0 & 69 & 33 \\
\hline Mar & 30.4 & 16.4 & 88 & 22 & 30.5 & 23.2 & 77 & 43 \\
\hline Apr & 36.6 & 19.7 & 87 & 12 & 32.0 & 26.0 & 83 & 54 \\
\hline May & 39.1 & 22.9 & 92 & 15 & 33.3 & 28.0 & 84 & 57 \\
\hline Jun & 42.6 & 26.4 & 68 & 12 & 32.5 & 28.8 & 91 & 69 \\
\hline Jul & 43.2 & 26.6 & 61 & 16 & 28.8 & 25.8 & 95 & 77 \\
\hline Aug & 44.8 & 26.4 & 47 & 8 & 27.4 & 24.1 & 97 & 81 \\
\hline Sep & 39.0 & 22.5 & 84 & 19 & 27.9 & 23.6 & 91 & 67 \\
\hline Oct & 34.3 & 19.1 & 86 & 18 & 30.4 & 23.5 & 82 & 50 \\
\hline Nov & 31.6 & 16.6 & 90 & 24 & 30.5 & 21.4 & 74 & 43 \\
\hline Dec & 27.6 & 13.8 & 88 & 36 & 29.0 & 20.9 & 72 & 37 \\
\hline
\end{tabular}


Moreover, while hourly weather data in Oman are very scarce, these eight locations benefit from considerable hourly weather data due to the fact that they all happen to be the bases for oilfields, refineries, and airports. Their coordinates and altitudes are shown in Table 1 . Location 1 is a relatively heavily populated town surrounded by a typical Arabian desert and is about $75 \mathrm{~km}$ from the coastline. Locations 2, 3, and 4 are major population centers characterized by high temperatures and high humidity and are located on the coastline. Locations 5 and 7 are oil fields located in the Arabian Desert of the Empty Quarter and are about 250 and $70 \mathrm{~km}$, respectively, away from the coastline. Location 6 is an island in the Indian Ocean. It is about 640 square kilometers and is about $20 \mathrm{~km}$ away from the mainland. Location 8 is a town with a moderate climate throughout the year and is famous as a summer resort in the region.

In the summer time, electrical power consumption is significantly higher than that in the winter time because of the high demand for air conditioning. In 2007, the demand went from 1,000 MW in January to 2,773 MW in July. This figure has been increasing at an annual growth rate of $9 \%$ and was expected to reach 4,634 MW in 2013 (AER-Oman, 2008). Currently, the government is launching long-term initiatives for the use of renewable energies in the country. Passive cooling was practiced in the past using empirical methodologies. Historically, high mass (Fig. 5) with ventilation was quite commonly practiced in the interior of the country, which has a climate characterized by lower humidity and a reasonably significant day-tonight temperature difference.

This study will allow a systematic approach to the determination of effective passive cooling strategies in the country using bioclimatic charts. As mentioned above, Givoni's charts were used in the study, and a quantitative measure is presented below based on the projection of the psychrometric parameters on the different zones in the chart. The weather data was processed and analyzed using MATLAB (MathWorks, Inc, Nattick, Massachusetts). The charts were also developed using the same software.

\section{Results and Discussions}

Table 2 shows the monthly mean dry bulb temperature and humidity for each location. The meteorological data were taken from a study by (Zurigat et al. 2003) in which the hourly reading for several years were statistically analyzed. As mentioned above, day and night temperature differences, humidity, and temperature were the variables used to decide a suitable technique for a given location.

Figure 6 shows the average temperature of each month for the eight locations. The non-coastal locations (1, 5 and 7$)$ exhibited high temperatures consis- tent with the time of year. July and August seemed to be the hottest months of the year. The rest of the coastline locations had slightly lower average temperatures, except for Locations 6 and 8 , which are affected by the Indian monsoon from June to September.

Another equally important criterion for the selection of passive cooling techniques is the day-to-night temperature difference. If this difference is small, thermal mass and night ventilation will not be effective enough to allow adequate cooling. Figure 7 shows this difference for the eight locations. For each location in a given month, a point represents the average day-tonight temperature difference. Non-costal locations had differences greater than $10^{\circ} \mathrm{C}$, which justifies using thermal mass as a passive cooling strategy in these locations.

In order to inspect for possible passive cooling opportunities, the hourly climatic readings for each of the locations are analyzed. The distribution of the average hourly readings for each month are projected on the bioclimatic chart. For each month, the average of the daily maximum temperature is calculated and matched with the average of the minimum daily absolute humidity to form the point $\left(\overline{\mathrm{T}}_{\text {max }}, \overline{\mathrm{W}}_{\text {min }}\right)$.

In a similar manner, the average of the daily minimum temperature is matched with the average daily minimum absolute humidity to form $\left(\overline{\mathrm{W}}_{\text {max }}, \overline{\mathrm{T}}_{\text {min }}\right)$. The placement of the line segment connecting the two points on the bioclimatic chart will determine the proper passive cooling strategy for that month. The mean values are shown in Table 3 along with the relative humidity. The construction of the line segment in the manner described above is good for enhancing readability of the chart. A very good match is found when comparing the inclusion of the line segment in each of the zones to the inclusion of the hourly data for the same months which indicates the reliability of the presentation.

Figures 8 to 15 show the Givoni charts for the eight locations based on the average minimum and maximum hourly temperature and humidity values shown in Table 3. Givoni charts are more qualitative. The inclusion of the line segment for each month in a given zone gives an approximate idea if the application of that method would be appropriate. One should also care about the diurnal temperature difference and whether the placement of the line segment within the zone is promising enough by checking the dry bulb temperature and humidity values.

Table $4 \mathrm{a} \& \mathrm{~b}$ shows the fractions of the projection of the hourly readings in each of the five zones for each month with the bold face figures indicating dayto-night temperature differences exceeding $10^{\circ} \mathrm{C}$. For instance, 0.8 means that for $80 \%$ of the hours, the tem- 
N Al-Azri, YH Zurigat and N Al-Rawahi

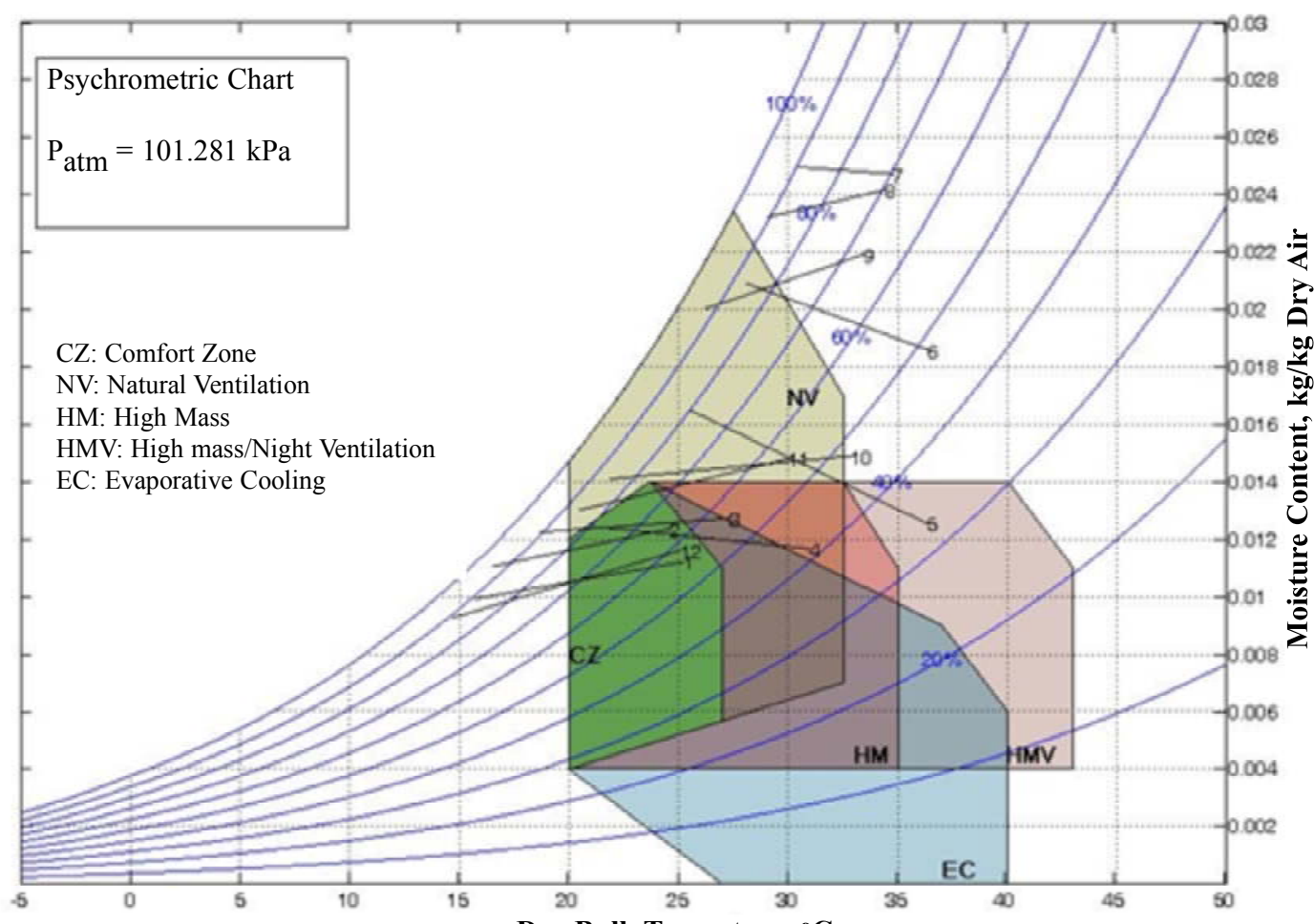

Dry Bulb Teperature, ${ }^{\circ} \mathrm{C}$

Figure 9. Givoni's bioclimatic chart for location (2), Majis

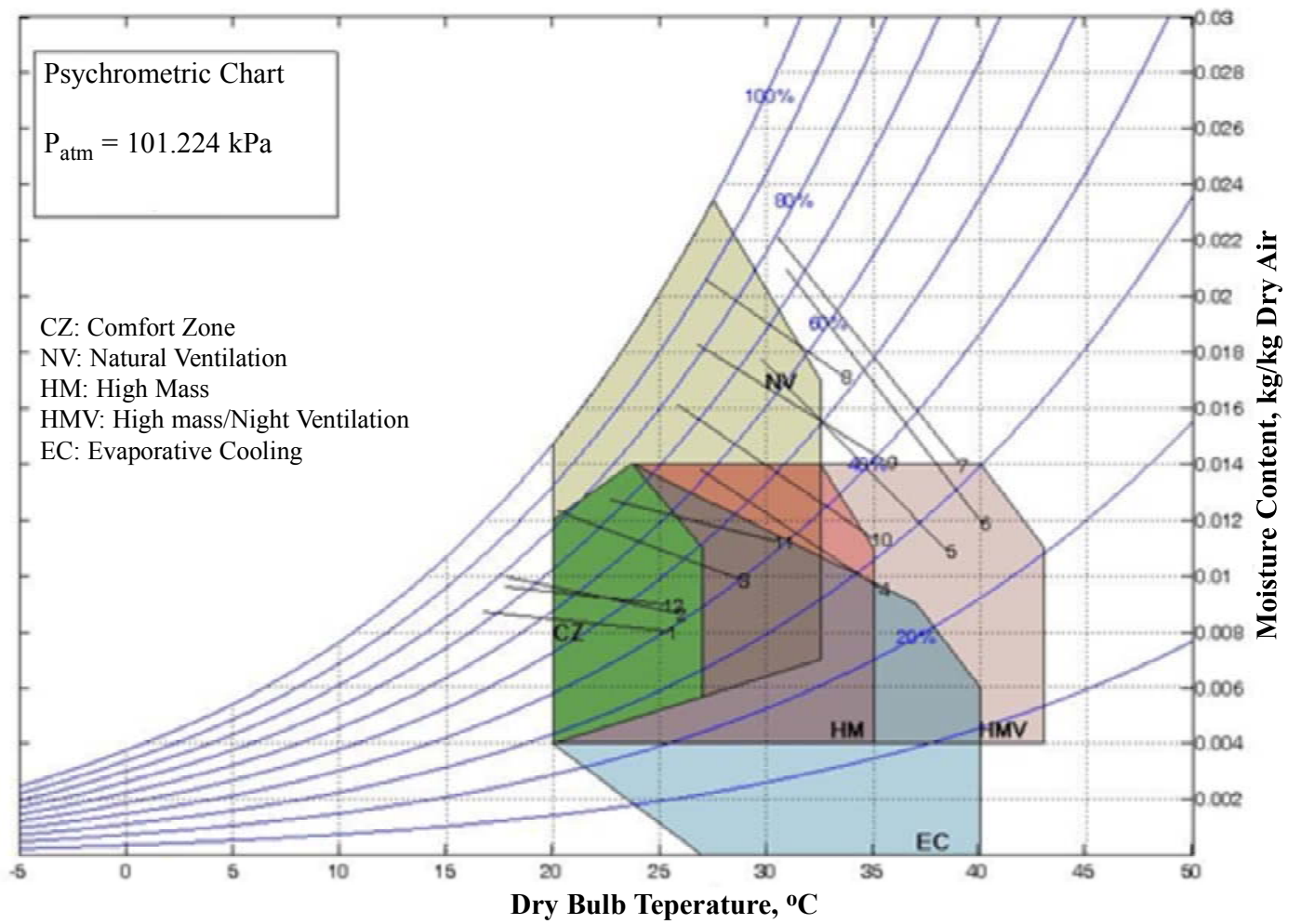

Figure 10. Givoni's bioclimatic chart for location (3), Seeb

perature and humidity readings would be contained within the zone of conditions appropriate for passive cooling mechanisms. Since the different zones overlap, the sum of the different zone does not have to add up to unity. The calculations of these figures could have been done to more decimal places. Such an effort, however, would have been superfluous since the yearly deviation of readings can be greater than the approximate figure used here.

From Fig. 8 and Table $4 a \& b$, one can see that, except for the months from June to September, passive cooling techniques would be quite effective in 


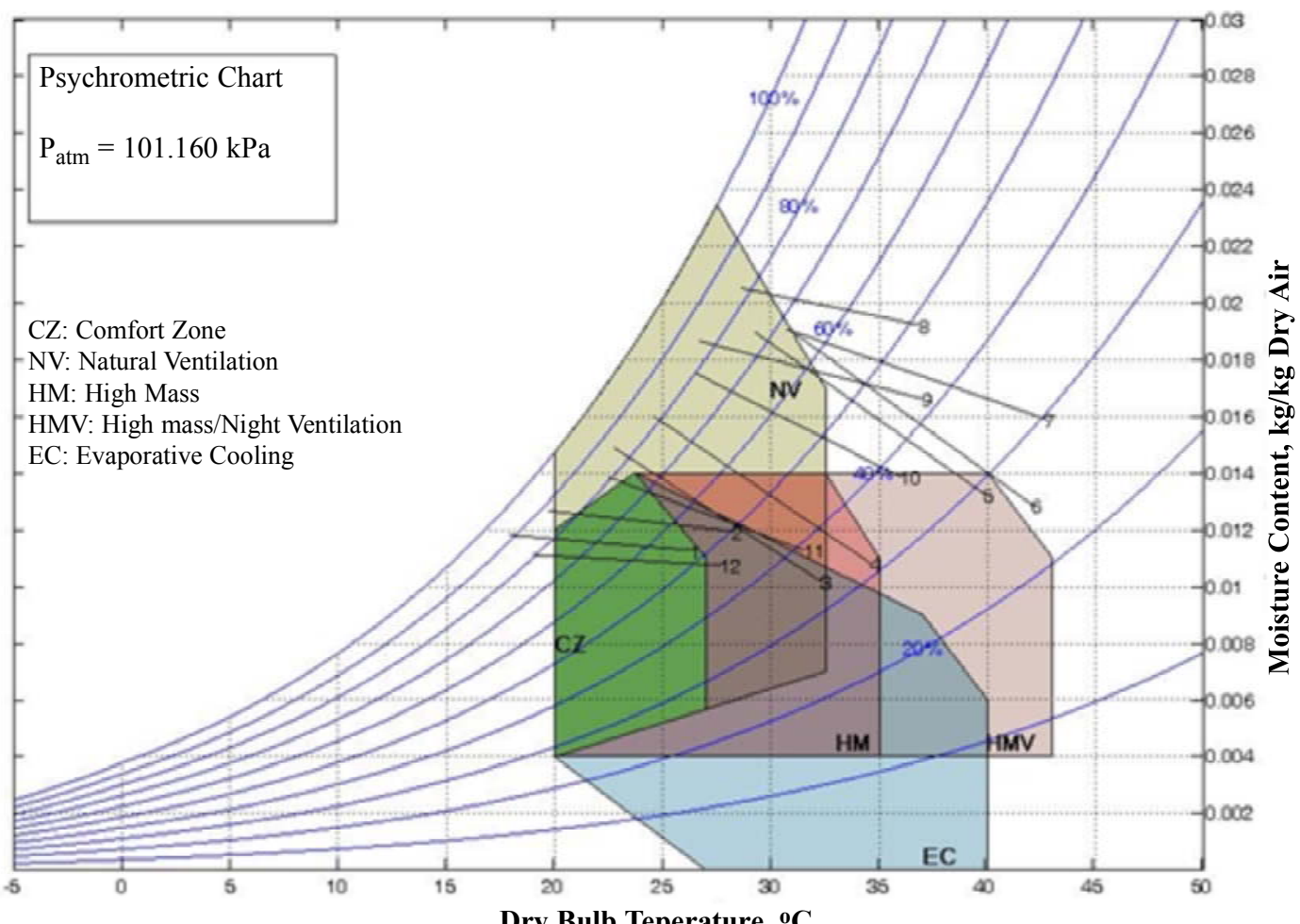

Figure 11. Givoni's bioclimatic chart for location (4), Sur

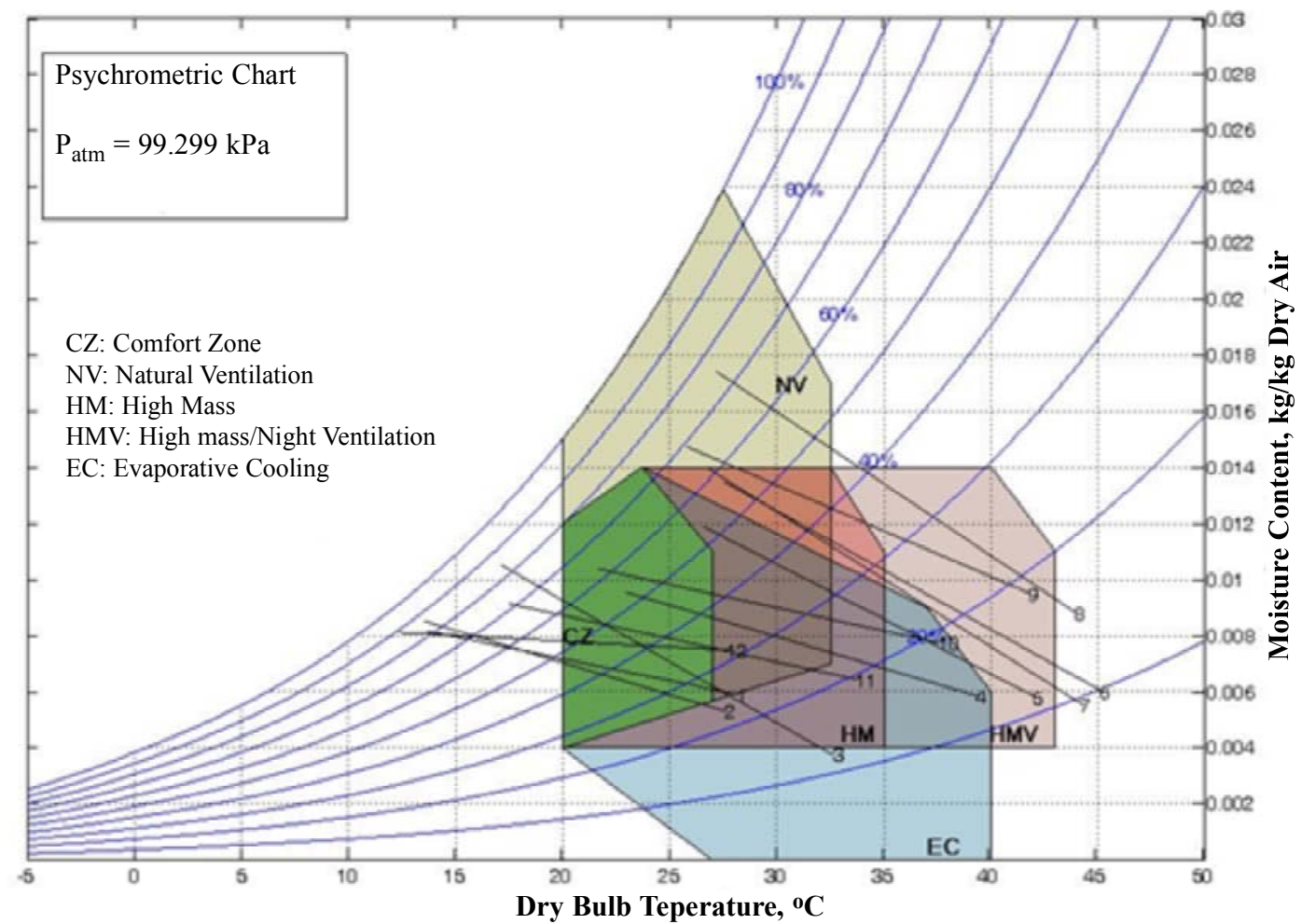

Figure 12. Givoni's bioclimatic chart for location (5), Fahud

Buraimi. In the months of December through February, solar heating would be needed but in March, May, October, and November, passive cooling would be a promising method for more than $70 \%$ of the time.

Location 2, Majis, proved itself a less desirable location for passive cooling (Fig. 9; Table 3). Except for April and May, the diurnal temperature difference is low and high humidity prevents the use of passive cooling and night ventilation. Air conditioning is necessary for most of the year in this location. 
N Al-Azri, YH Zurigat and N Al-Rawahi

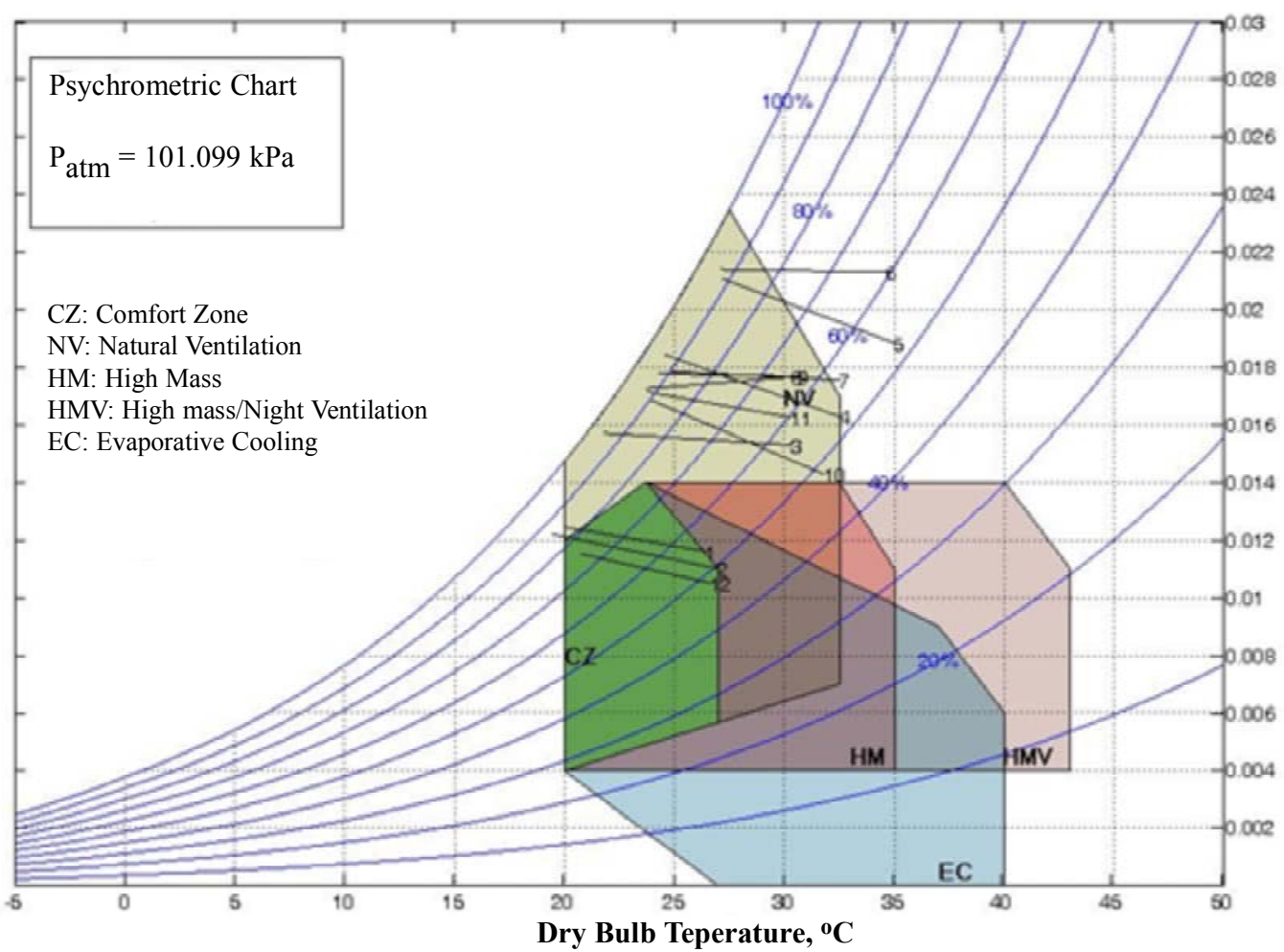

Figure 13. Givoni's bioclimatic chart for location (6), Masira

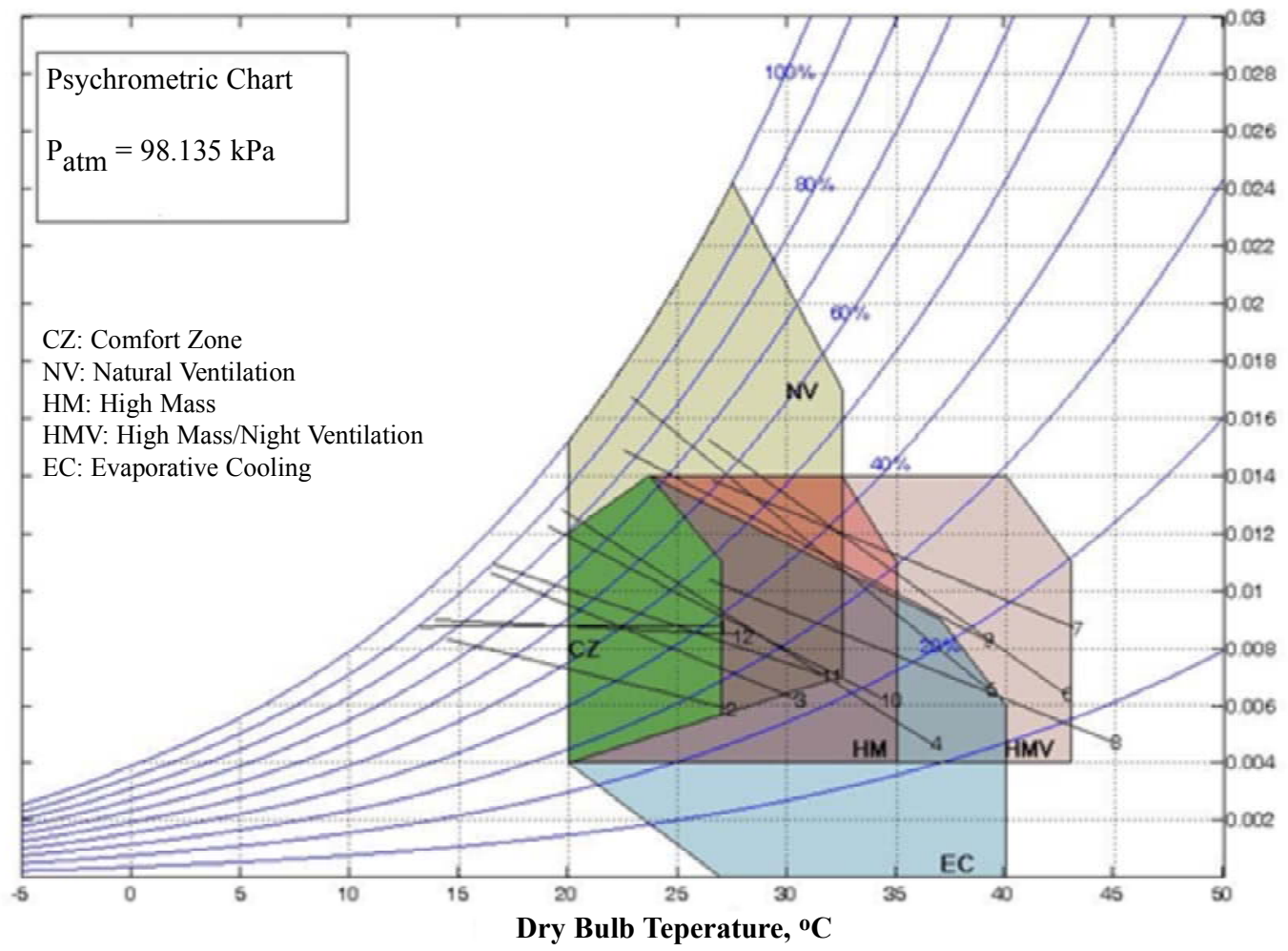

Figure 14. Givoni's bioclimatic chart for location (7), Marmul

Location 3, Seeb, which is on the coastline, exhibited a similar result to Location 2 (Fig. 10; Table $4 a \& b)$. However, the weather data showed that Seeb falls within the $\mathrm{CZ}$ for a longer and more reassuring period from November to March. Location 4, Sur, followed somewhat the same trend as Location 2 (Fig. 11, Table $4 a \& b)$. The climate was quite comfortable from December to February, and passive cooling would be 
Table 4a. The projection of weather data in the different zones for passive cooling Strategies (Buraimi, Majis, Seeb and Sur)

\begin{tabular}{|c|c|c|c|c|c|c|c|c|c|c|}
\hline & \multicolumn{5}{|c|}{ 1. Buraimi } & \multicolumn{5}{|c|}{ 2. Maj is } \\
\hline & $\mathrm{CZ}$ & NV & $\mathrm{HM}$ & HMV & $\mathrm{EC}$ & $\mathrm{CZ}$ & NV & $\mathrm{HM}$ & HMV & $\mathrm{EC}$ \\
\hline Jan & 0.4 & 0.4 & 0.4 & 0.4 & 0.4 & 0.6 & 0.6 & 0.6 & 0.6 & 0.6 \\
\hline Feb & 0.5 & 0.5 & 0.5 & 0.5 & 0.5 & 0.6 & 0.6 & 0.6 & 0.6 & 0.6 \\
\hline Mar & 0.5 & 0.8 & 0.8 & 0.8 & 0.8 & 0.5 & 0.8 & 0.8 & 0.8 & 0.7 \\
\hline Apr & 0.4 & 0.7 & 0.9 & 1.0 & 0.7 & 0.5 & 1.0 & 1.0 & 1.0 & 0.8 \\
\hline May & 0.1 & 0.4 & 0.6 & 1.0 & 0.3 & 0.0 & 0.6 & 0.0 & 0.4 & 0.0 \\
\hline Jun & 0.0 & 0.3 & 0.0 & 0.0 & 0.0 & 0.0 & 0.3 & 0.0 & 0.0 & 0.0 \\
\hline Jul & 0.0 & 0.1 & 0.0 & 0.0 & 0.0 & 0.0 & 0.0 & 0.0 & 0.0 & 0.0 \\
\hline Aug & 0.0 & 0.1 & 0.0 & 0.0 & 0.0 & 0.0 & 0.0 & 0.0 & 0.0 & 0.0 \\
\hline Sep & 0.0 & 0.4 & 0.0 & 0.0 & 0.0 & 0.0 & 0.5 & 0.0 & 0.0 & 0.0 \\
\hline Oct & 0.2 & 0.6 & 0.8 & 1.0 & 0.5 & 0.0 & 1.0 & 0.0 & 0.0 & 0.0 \\
\hline Nov & 0.6 & 0.9 & 0.9 & 0.9 & 0.9 & 0.2 & 1.0 & 0.4 & 0.4 & 0.2 \\
\hline \multirow[t]{3}{*}{ Dec } & 0.6 & 0.6 & 0.6 & 0.6 & 0.6 & 0.5 & 0.5 & 0.5 & 0.5 & 0.5 \\
\hline & \multicolumn{5}{|c|}{ 3. Se eb } & \multicolumn{5}{|c|}{ 4. Sur } \\
\hline & $\mathrm{CZ}$ & NV & $\mathrm{HM}$ & HMV & $\mathrm{EC}$ & $\mathrm{CZ}$ & NV & $\mathrm{HM}$ & HMV & $\mathrm{EC}$ \\
\hline Jan & 0.6 & 0.6 & 0.6 & 0.6 & 0.6 & 0.8 & 0.8 & 0.8 & 0.8 & 0.8 \\
\hline Feb & 0.7 & 0.7 & 0.7 & 0.7 & 0.7 & 0.5 & 1.0 & 0.8 & 0.8 & 0.8 \\
\hline Mar & 0.8 & 1.0 & 1.0 & 1.0 & 1.0 & 0.0 & 1.0 & 0.8 & 0.8 & 0.5 \\
\hline Apr & 0.0 & 0.7 & 1.0 & 1.0 & 0.0 & 0.0 & 0.8 & 0.6 & 0.6 & 0.0 \\
\hline May & 0.0 & 0.3 & 0.0 & 0.5 & 0.0 & 0.0 & 0.3 & 0.0 & 0.1 & 0.0 \\
\hline Jun & 0.0 & 0.0 & 0.0 & 0.2 & 0.0 & 0.0 & 0.0 & 0.0 & 0.0 & 0.0 \\
\hline Jul & 0.0 & 0.0 & 0.0 & 0.0 & 0.0 & 0.0 & 0.1 & 0.0 & 0.0 & 0.0 \\
\hline Aug & 0.0 & 0.7 & 0.0 & 0.0 & 0.0 & 0.0 & 0.2 & 0.0 & 0.0 & 0.0 \\
\hline Sep & 0.0 & 0.7 & 0.0 & 0.0 & 0.0 & 0.0 & 0.5 & 0.0 & 0.0 & 0.0 \\
\hline Oct & 0.0 & 0.7 & 0.5 & 0.6 & 0.0 & 0.0 & 0.6 & 0.0 & 0.0 & 0.0 \\
\hline Nov & 0.4 & 1.0 & 1.0 & 1.0 & 1.0 & 0.2 & 1.0 & 0.9 & 0.9 & 0.7 \\
\hline Dec & 0.7 & 0.7 & 0.7 & 0.7 & 0.7 & 0.8 & 0.9 & 0.9 & 0.9 & 0.9 \\
\hline
\end{tabular}

*CZ: Conform Zone, NV: Night Ventilation, HM: High Mass, HMV: High Mass with Night Ventilation EC: Evaporative Cooling

Bold Figures: Diurnal temperature difference greater than $10^{\circ} \mathrm{C}$

feasible only in April. The diurnal temperature difference was greater than $10^{\circ} \mathrm{C}$ in some months, but the lower end of the temperature range was still too high, necessitating air conditioning.

Locations 5 and 7 (Figs. 12 and 14, Table 4a\&b) depicted similar trends to one another. The diurnal temperature difference was always greater than $10^{\circ} \mathrm{C}$ and passive cooling techniques would be quite effective for most of the year. The broadness of the difference in diurnal temperature can be extrapolated from the long segments on the Givoni chart. Location 6, Masirah, proved less acceptable as a location amenable to passive cooling as a substitute for mechanical cooling (Fig. 13, Table 4a\&b). The humidity in Masirah is quite high $(60 \%)$ and, although December to February have temperatures in the $\mathrm{CZ}$, they experience high humidity.
In Location 8, the temperatures from November to March were within the range acceptable for a passive cooling zone, but the low diurnal temperature difference may discourage its application (Fig. 15; Table $4 a \& b)$.

\section{Conclusions}

The applicability of the different passive cooling techniques is controlled by a spectrum of factors related not only to climatic changes but also to cultural and situational factors. It is far from realistic to dictate firm prerequisites and provide distinctive instructions on when the mechanisms should be applied and what passive technique to use. However, climatic factors are always the most relevant. Early design tools can provide deeper insight into the robustness of a given strat- 
Table 4b. The projection of weather data in the different zones for passive cooling strategies (Fahid, Masirah, Marmul and Salalah)

\begin{tabular}{lllllllllll}
\hline & \multicolumn{9}{c}{$\mathbf{5 . ~ F a h ~ u d ~}$} & \multicolumn{6}{c}{$\mathbf{6 .}$ Masirah } \\
\hline & CZ & NV & HM & HMV & EC & CZ & NV & HM & HMV & EC \\
Jan & $\mathbf{0 . 5}$ & $\mathbf{0 . 5}$ & $\mathbf{0 . 6}$ & $\mathbf{0 . 6}$ & $\mathbf{0 . 6}$ & 0.8 & 1.0 & 0.9 & 0.9 & 0.9 \\
Feb & $\mathbf{0 . 5}$ & $\mathbf{0 . 5}$ & $\mathbf{0 . 5}$ & $\mathbf{0 . 5}$ & $\mathbf{0 . 5}$ & 0.9 & 0.9 & 0.9 & 0.9 & 0.9 \\
Mar & $\mathbf{0 . 5}$ & $\mathbf{0 . 5}$ & $\mathbf{0 . 8}$ & $\mathbf{0 . 8}$ & $\mathbf{0 . 8}$ & 0.0 & 1.0 & 0.0 & 0.0 & 0.0 \\
Apr & $\mathbf{0 . 2}$ & $\mathbf{0 . 6}$ & $\mathbf{0 . 7}$ & $\mathbf{1 . 0}$ & $\mathbf{1 . 0}$ & 0.0 & 1.0 & 0.0 & 0.0 & 0.0 \\
May & $\mathbf{0 . 0}$ & $\mathbf{0 . 4}$ & $\mathbf{0 . 5}$ & $\mathbf{1 . 0}$ & $\mathbf{0 . 8}$ & 0.0 & 0.4 & 0.0 & 0.0 & 0.0 \\
Jun & $\mathbf{0 . 0}$ & $\mathbf{0 . 3}$ & $\mathbf{0 . 4}$ & $\mathbf{0 . 9}$ & $\mathbf{0 . 0}$ & 0.0 & 0.3 & 0.0 & 0.0 & 0.0 \\
Jul & $\mathbf{0 . 0}$ & $\mathbf{0 . 3}$ & $\mathbf{0 . 5}$ & $\mathbf{0 . 9}$ & $\mathbf{0 . 1}$ & 0.0 & 0.9 & 0.0 & 0.0 & 0.0 \\
Aug & $\mathbf{0 . 0}$ & $\mathbf{0 . 3}$ & $\mathbf{0 . 0}$ & $\mathbf{0 . 5}$ & $\mathbf{0 . 0}$ & 0.0 & 1.0 & 0.0 & 0.0 & 0.0 \\
Sep & $\mathbf{0 . 0}$ & $\mathbf{0 . 4}$ & $\mathbf{0 . 4}$ & $\mathbf{0 . 9}$ & $\mathbf{0 . 0}$ & 0.0 & 1.0 & 0.0 & 0.0 & 0.0 \\
Oct & $\mathbf{0 . 3}$ & $\mathbf{0 . 7}$ & $\mathbf{0 . 8}$ & $\mathbf{1 . 0}$ & $\mathbf{1 . 0}$ & 0.0 & 1.0 & 0.0 & 0.0 & 0.0 \\
Nov & $\mathbf{0 . 4}$ & $\mathbf{0 . 7}$ & $\mathbf{0 . 8}$ & $\mathbf{0 . 8}$ & $\mathbf{0 . 8}$ & 0.0 & 1.0 & 0.0 & 0.0 & 0.0 \\
Dec & $\mathbf{0 . 5}$ & $\mathbf{0 . 5}$ & $\mathbf{0 . 5}$ & $\mathbf{0 . 5}$ & $\mathbf{0 . 5}$ & 1.0 & 1.0 & 1.0 & 1.0 & 1.0 \\
& & & $\mathbf{7 . ~ M a r m u l}$ & & & & $\mathbf{8 . ~ S a l a l a h}$ & \\
& CZ & NV & HM & HMV & EC & CZ & NV & HM & HMV & EC \\
Jan & $\mathbf{0 . 5}$ & $\mathbf{0 . 5}$ & $\mathbf{0 . 5}$ & $\mathbf{0 . 5}$ & $\mathbf{0 . 5}$ & 0.8 & 0.9 & 0.9 & 0.9 & 0.9 \\
Feb & $\mathbf{0 . 5}$ & $\mathbf{0 . 6}$ & $\mathbf{0 . 6}$ & $\mathbf{0 . 6}$ & $\mathbf{0 . 6}$ & 0.8 & 0.9 & 0.9 & 0.9 & 0.9 \\
Mar & $\mathbf{0 . 5}$ & $\mathbf{0 . 7}$ & $\mathbf{0 . 7}$ & $\mathbf{0 . 7}$ & $\mathbf{0 . 7}$ & 0.1 & 1.0 & 1.0 & 1.0 & 0.6 \\
Apr & $\mathbf{0 . 4}$ & $\mathbf{0 . 7}$ & $\mathbf{0 . 8}$ & $\mathbf{0 . 9}$ & $\mathbf{0 . 9}$ & 0.0 & 1.0 & 0.0 & 0.0 & 0.0 \\
May & $\mathbf{0 . 0}$ & $\mathbf{0 . 6}$ & $\mathbf{0 . 5}$ & $\mathbf{0 . 7}$ & $\mathbf{0 . 4}$ & 0.0 & 0.6 & 0.0 & 0.0 & 0.0 \\
Jun & $\mathbf{0 . 0}$ & $\mathbf{0 . 4}$ & $\mathbf{0 . 4}$ & $\mathbf{0 . 9}$ & $\mathbf{0 . 0}$ & 0.0 & 0.0 & 0.0 & 0.0 & 0.0 \\
Jul & $\mathbf{0 . 0}$ & $\mathbf{0 . 4}$ & $\mathbf{0 . 5}$ & $\mathbf{1 . 0}$ & $\mathbf{0 . 0}$ & 0.0 & 1.0 & 0.0 & 0.0 & 0.0 \\
Aug & $\mathbf{0 . 0}$ & $\mathbf{0 . 3}$ & $\mathbf{0 . 5}$ & $\mathbf{0 . 9}$ & $\mathbf{0 . 7}$ & 0.0 & 1.0 & 0.0 & 0.0 & 0.0 \\
Sep & $\mathbf{0 . 0}$ & $\mathbf{0 . 6}$ & $\mathbf{0 . 6}$ & $\mathbf{0 . 9}$ & $\mathbf{0 . 0}$ & 0.0 & 1.0 & 0.0 & 0.0 & 0.0 \\
Oct & $\mathbf{0 . 5}$ & $\mathbf{0 . 8}$ & $\mathbf{0 . 9}$ & $\mathbf{0 . 9}$ & $\mathbf{0 . 9}$ & 0.0 & 1.0 & 0.3 & 0.3 & 0.0 \\
Nov & $\mathbf{0 . 5}$ & $\mathbf{0 . 8}$ & $\mathbf{0 . 8}$ & $\mathbf{0 . 8}$ & $\mathbf{0 . 8}$ & 0.5 & 1.0 & 1.0 & 1.0 & 0.9 \\
Dec & $\mathbf{0 . 5}$ & $\mathbf{0 . 6}$ & $\mathbf{0 . 6}$ & $\mathbf{0 . 6}$ & $\mathbf{0 . 6}$ & 0.8 & 1.0 & 1.0 & 1.0 & 1.0 \\
\hline
\end{tabular}

*CZ: Conform Zone, NV: Night Ventilation, HM: High Mass, HMV: High Mass with Night Ventilation

EC: Evaporative Cooling, Bold Figures: Diurnal temperature difference greater than $10^{\circ} \mathrm{C}$

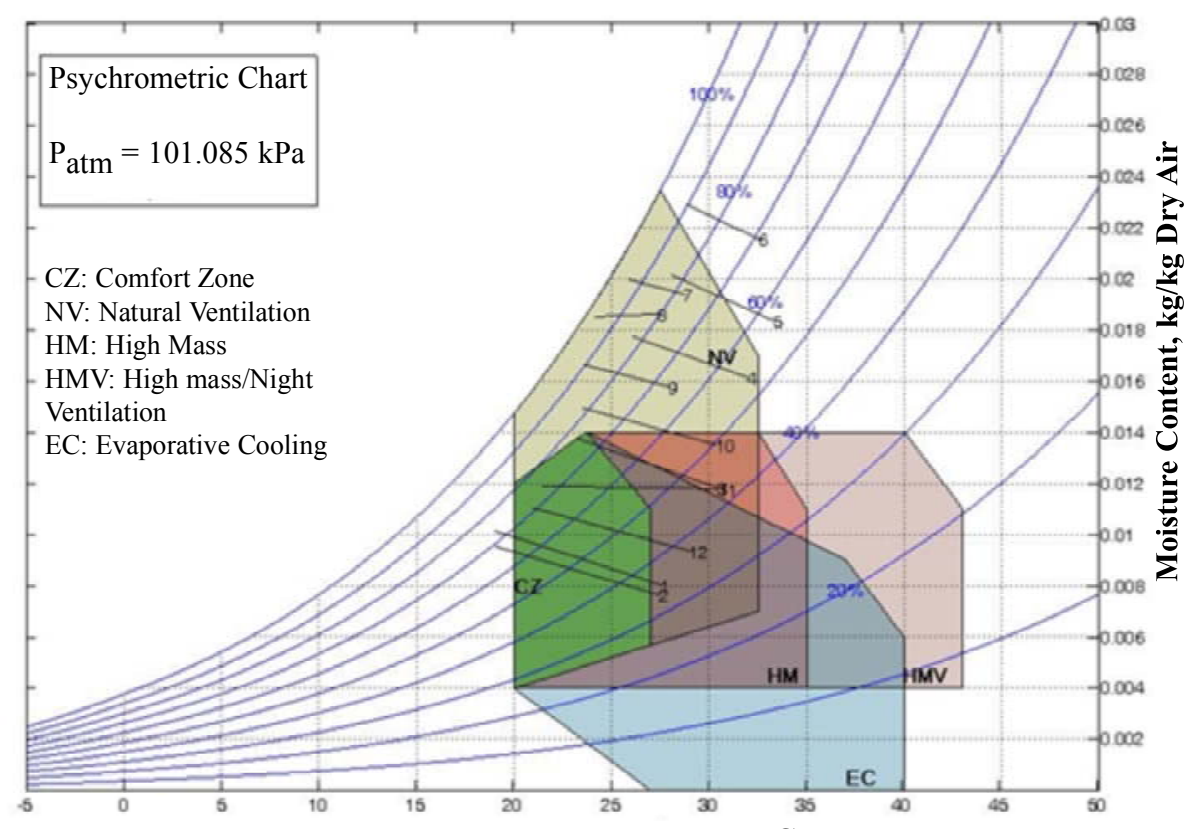

Dry Bulb Teperature, ${ }^{\circ} \mathrm{C}$

Figure 15. Givoni's bioclimatic chart for location (8), Salalah 
egy and its required tradeoffs. This study considers that aspect in the application of passive cooling. For each of the eight locations widely scattered around Oman, 8,760 hourly readings were used (Zurigat et al. 2003). MATLAB codes were developed to perform the calculations, and data were plotted on Givoni's charts. This graphical representation was quantified by calculating the portion of inclusion in each of the zones. The average diurnal temperature difference was also calculated and is shown on the tabulated representation. It can be concluded that passive cooling strategies present energy saving opportunities, especially in the interior of the country (eg. Buraimi, Fahud, and Marmul). The slight swing in day-to-night temperatures would present an obstacle to the implementation of high mass with night ventilation in some coastal locations (eg. Majis, Seeb, and Sur). Salalah and Masirah enjoy relatively more comfortable weather and exhibit less variation throughout the day because of the presence of the Indian monsoon.

\section{References}

Authority for Electricity Regulation, Oman (AEROman) (2008), Study on renewable energy resources. Final Report AER, Muscat, Oman.

Artmann N, Manz H, Heiselberg P (2007), Climatic potential for passive cooling of buildings by nighttime ventilation in Europe. Applied Energy 84:187-201.

Auliciems A (1981), Towards a psychophysiological model of thermal perception. Int. J. Biometer 25:109-122.

Breesch H, Janssens A (2007), Reliable design of natural night ventilation using building simulation. Proceedings of the Thermal Performance of the Exterior Envelopes of Whole Buildings X International Conference 1-14, Clearwater Beach, Florida.

Breesch, H, Janssens A (2010), Performance evaluation of passive cooling in office buildings based on uncertainty and sensitivity analysis. Solar Energy 84:1453-1467.

Givoni B (1992), Comfort, climate analysis and building design guidelines. Energy and Buildings 1:1123.

Givoni B (1994), Passive and low energy cooling of buildings. Van Nostrand Reinhold, New York.

Givoni B (2009), Indoor temperature reduction by passive cooling systems. Solar Energy 85:16921726.

Fanger PO (1972), Thermal confort: analysis and applications in environmental engineering. MaGraw-Hill, New York.

Haase M, Amato A (2009), An investigation of the potential for natural ventilation and building ori- entation to achieve thermal comfort in warm and humid climates. Solar Energy 83:389-399.

Humphreys MA (1978), Outdoor temperature and comfort indoors. Building Research and Practice 6:92-105.

International Energy Agency (IEA) (2006), World energy outlook: 2006 report. IEA, Paris.

Kolokotroni M (1995), Night ventilation in commercial buildings. In: Annex 28: Review of Low Energy Cooling Technologies Subtask 1, 7-11. International Energy Agency, Ottawa.

Lomas KJ, Fiala D, Cook MJ, Copper PC (2004), Building bioclimatic charts for non-domestic buildings and passive downdraught evaporative cooling. Building and Environment 39:661-676.

MacPherson RK (1973), Thermal stress and thermal comfort. Ergonomics 16:1366-5847.

MNE, Ministry of National Economy (2007, Statistical Year Book, MNE, Muscat, Oman.

Olgyay V (1963), Design with climate, bioclimatic approach and architectural regonalism. Princeton University Press, Princeton, New Jersey.

Reardon C (2010), Home technical manual. From: http://www.yourhome.gov.au/technical/. Accessed: January 20, 2013.

Santamouris M, Asimakopoulos D (1996), Passive Cooling of Buildings. Routledge, London, UK.

Sayigh A, Marafia AH (1998), Thermal comfort and the development of bioclimatic concept in building design. Renewable and Sustainable Energy Reviews 2:3-24.

Shaviv E, Yezioro A, Capeluto IG (2001), Thermal mass and night ventilation as passive cooling design strategy. Renewable Energy 24:445-452.

Szoloky SV (1986), Climate analysis based on psychometric chart. Ambient Energy 7:171-181.

Szokolay SV (2004), Introduction to Architectural Science: The basis of sustainable design. Architectural Press, Oxford, UK.

The American Society of Heating, Refrigerating and Air Conditioning Engineers (ASHRAE) (2009), ASHRAE Handbook Fundementals. ASHRAE, Atlanta, GA.

United Nations Environment Program (UNEP) (2011), Global trends in renewable energy investment. Bloomberg New Energy Finance, Frankfurt, Germany.

Watson D (1981), Analysis of weather data for determinimg appropriate climate control strategies in archetectural design. Proceedings of the International Passive and Hybrid Cooling Conference. Haisley R., Miami Beach, Florida.

Zurigat YH, Sawaqed N, Al-Hinai H, Jubran B (2003), Development of typical meteorological years for different climatic regions in Oman. Final Report, Petroleum Development Oman, Muscat, Oman. 